\title{
Review Article \\ Cellular Mechanisms of Liver Regeneration and Cell-Based Therapies of Liver Diseases
}

\author{
Irina V. Kholodenko and Konstantin N. Yarygin \\ Institute of Biomedical Chemistry, Moscow, Russia \\ Correspondence should be addressed to Irina V. Kholodenko; irkhol@yandex.ru \\ Received 13 September 2016; Revised 29 November 2016; Accepted 27 December 2016; Published 22 January 2017 \\ Academic Editor: Udayan Apte
}

Copyright (C) 2017 Irina V. Kholodenko and Konstantin N. Yarygin. This is an open access article distributed under the Creative Commons Attribution License, which permits unrestricted use, distribution, and reproduction in any medium, provided the original work is properly cited.

\begin{abstract}
The emerging field of regenerative medicine offers innovative methods of cell therapy and tissue/organ engineering as a novel approach to liver disease treatment. The ultimate scientific foundation of both cell therapy of liver diseases and liver tissue and organ engineering is delivered by the in-depth studies of the cellular and molecular mechanisms of liver regeneration. The cellular mechanisms of the homeostatic and injury-induced liver regeneration are unique. Restoration of the mass of liver parenchyma is achieved by compensatory hypertrophy and hyperplasia of the differentiated parenchymal cells, hepatocytes, while expansion and differentiation of the resident stem/progenitor cells play a minor or negligible role. Participation of blood-borne cells of the bone marrow origin in liver parenchyma regeneration has been proven but does not exceed $1-2 \%$ of newly formed hepatocytes. Liver regeneration is activated spontaneously after injury and can be further stimulated by cell therapy with hepatocytes, hematopoietic stem cells, or mesenchymal stem cells. Further studies aimed at improving the outcomes of cell therapy of liver diseases are underway. In case of liver failure, transplantation of engineered liver can become the best option in the foreseeable future. Engineering of a transplantable liver or its major part is an enormous challenge, but rapid progress in induced pluripotency, tissue engineering, and bioprinting research shows that it may be doable.
\end{abstract}

\section{Introduction}

Liver diseases pose a significant problem for national health care systems throughout the world [1-4]. Persisting hepatitis infection, alcoholism, and hereditary liver metabolic disorders are the ultimate cause of growing incidence of acute and chronic liver failure associated with high morbidity and mortality. In case of liver failure clinical approaches currently in use are ineffective with the exception of organ transplantation. While allogeneic liver transplantation is an efficient method, its practical application is curbed by the limited supply of donor organs, immunological side effects, and economic reasons.

The development of alternative methods of treatment of liver pathology is in great demand. The emerging field of regenerative medicine offers novel approaches to liver disease treatment based on a remarkable progress in basic biomedical research during the last 20-30 years. At present, cell therapy (injection or transfusion of cell suspensions) and tissue/organ engineering are the main methods of regenerative medicine studied in the experimental setup and tested clinically. Cell transplantation is aimed at repopulating liver tissue with hepatocytes, to boost the recipient's own liver regeneration capacity and enhance restoration of its structure and function. Compared to organ transplantation or organ/tissue engineering, cell therapy is much less invasive and expensive. On the other hand, organ engineering has the potential to solve the problem of liver donor shortage.

Obviously, the ultimate scientific foundation of both cell therapy of liver diseases and liver tissue and organ engineering should be delivered by the studies of cellular and molecular mechanisms of liver regeneration operating under physiological conditions (homeostatic regeneration), during enhanced functional loading (adaptive regeneration), or after damage caused by disease, poisoning, or trauma (injury-induced regeneration) [5]. Classical textbooks of histology, such as the 9th edition of Ham's Histology [6], used to give the following list of liver cell types: hepatocytes, 
cholangiocytes (biliary epithelial cells, bile duct epithelium), hepatic macrophages (Kupffer cells), fenestrated endothelium of vascular sinusoids, cellular elements of other blood vessels, Ito cells (stellate cells), stromal fibroblasts, lymphatic vessel cells, lymphocytes and other immune cells, and nerve elements. Later the so-called oval cells were added to the list $[7,8]$. Liver hosts a population of stem/progenitor cells, which in rodents includes oval cells [9]. Cell fate experiments suggested that stellate cells can also be the precursors of liver epithelial cells $[10,11]$.

There are two extensively studied mechanisms of liver regeneration: compensatory hyperplasia of hepatocytes and stem/progenitor cell-mediated regeneration. Molecular and cellular events taking place during compensatory hyperplasia are relatively well characterized, while the alternative regeneration mechanism has not been fully disclosed yet. Except resident liver cells, this role has been attributed to bloodborne cells of the bone marrow origin [12-14]. Stellate cells are an important element of the machinery of liver regeneration being part of liver stem cell niche, supporting regeneration at early stages by secreting growth factors and inducing regeneration arrest after restoration of normal organ mass [15].

Research carried out with animal models showed that methods of regenerative medicine can provide beneficial effects surpassing those delivered by any other therapeutic approach excluding donor liver transplantation and that the mechanisms of those effects involve replacement of damaged cells or tissue and stimulation of the animal's own regenerative potential. Experimental results provided a solid basis for initial clinical research. Limited experience with human patients seems to confirm some of the experimental results.

The scope of this paper is to review the mechanisms of liver regeneration and to describe current approaches aimed at enhancing liver regenerative capacities and at creating new engineered liver tissue and ultimately the whole engineered organ.

\section{Histological Structure of Liver Tissue}

The structural organization of liver tissue schematically presented in Figure 1 is rather uniform throughout the whole organ and reflects its metabolic and secretory functions [6]. Hepatocytes are quantitatively predominant cells constituting about $80 \%$ of total liver mass. They form trabeculae each composed of two rows of cells. Spaces between the hepatocyte rows form biliary canaliculi filled with bile evacuated to the bile ductules through the canals of Hering lined by hepatocytes and bile duct epithelial cells. Space between the trabeculae is occupied by blood sinusoids formed by fenestrated endothelium and lined with liver macrophages named Kupffer cells. The planar space between trabeculae and the fenestrated endothelium providing the maximum contact of hepatocytes with blood is called the space of Disse. Scattered among hepatocytes and contacting the spaces of Disse are Ito cells (liver stellate cells) containing lipids and vitamin A. Besides Kupffer cells, liver hosts other immune cells including resident natural killers (pit cells), conventional NK cells, and dendritic cells.

Liver hosts a pool of cells with combined characteristics of stem cells and progenitor cells [9]. Conventionally, liver stem/progenitor cells (LSPCs) are thought to step in the regeneration process after massive liver tissue necrosis caused by toxic assault or other reasons, when hepatocyte proliferation is constrained. In the literature cells with LSPC characteristics are also called hepatic stem/progenitor cells (HSPCs), liver progenitor cells (LPCs), or hepatic progenitor cells (HPCs). LSPCs reside in the ductules and canals of Hering. Though their role in liver regeneration is uncertain, LSPCs are considered an attractive starting material for the cell therapy of liver diseases and liver tissue engineering [16$18]$.

Hepatic trabeculae are arranged into lobules where trabeculae radiate from the center occupied by the central vein to the periphery of the lobule. Lobules are separated by connective tissue septae which in humans are very thin. Each lobule is surrounded by six neighboring lobules. Areas where the edges of rectangular faces of three lobules meet form the so-called portal areas containing a portal vein, a hepatic artery, and a bile duct. Blood flows from branches of the portal vein through sinusoids where it gets mixed with blood from branches of the hepatic artery. This mixture drains through the sinusoids into a central vein and further into the terminal branches of the hepatic vein. After collecting blood from its branches, the hepatic vein goes into the inferior vena cava. Metabolism and other properties of hepatocytes depend upon their position at the porto-central axis of a lobule [19]. Normal liver tissue contains relatively small amount of extracellular matrix concentrated primarily in the outer connective tissue capsule of the organ.

\section{Crucial Role of Hepatocyte Proliferation and Hypertrophy in Liver Regeneration after Partial Hepatectomy}

Liver has a remarkable ability to regenerate its mass after injury. Eighty-five years ago Higgins and Anderson [20] were the first to demonstrate that after removal of two-thirds of rat liver the organ regains its initial mass and at this point regrowth is halted. This result has been many times confirmed in experiments with laboratory rodents [21]. In rat and mouse studies restoration of the organ's mass occurred via compensatory hypertrophy and hyperplasia of hepatocytes in the intact lobes, while removed lobes and segments did not regrow. Rodent liver consists of five lobes and three of them can be easily removed without substantial damage to the other two. The remaining two lobes increase their size and restore the organ mass. In mice and rats this takes 5-7 days. In case of partial hepatectomy, functional regeneration is not accompanied by full anatomical regeneration suggesting that liver regeneration induced by the removal of its part is guided by functional impairment. Importantly, organ regeneration occurring after living-donor liver transplantation in humans seems to follow a similar route. Indeed, after the operation both parts of donor's liver (that remaining in donor's body 


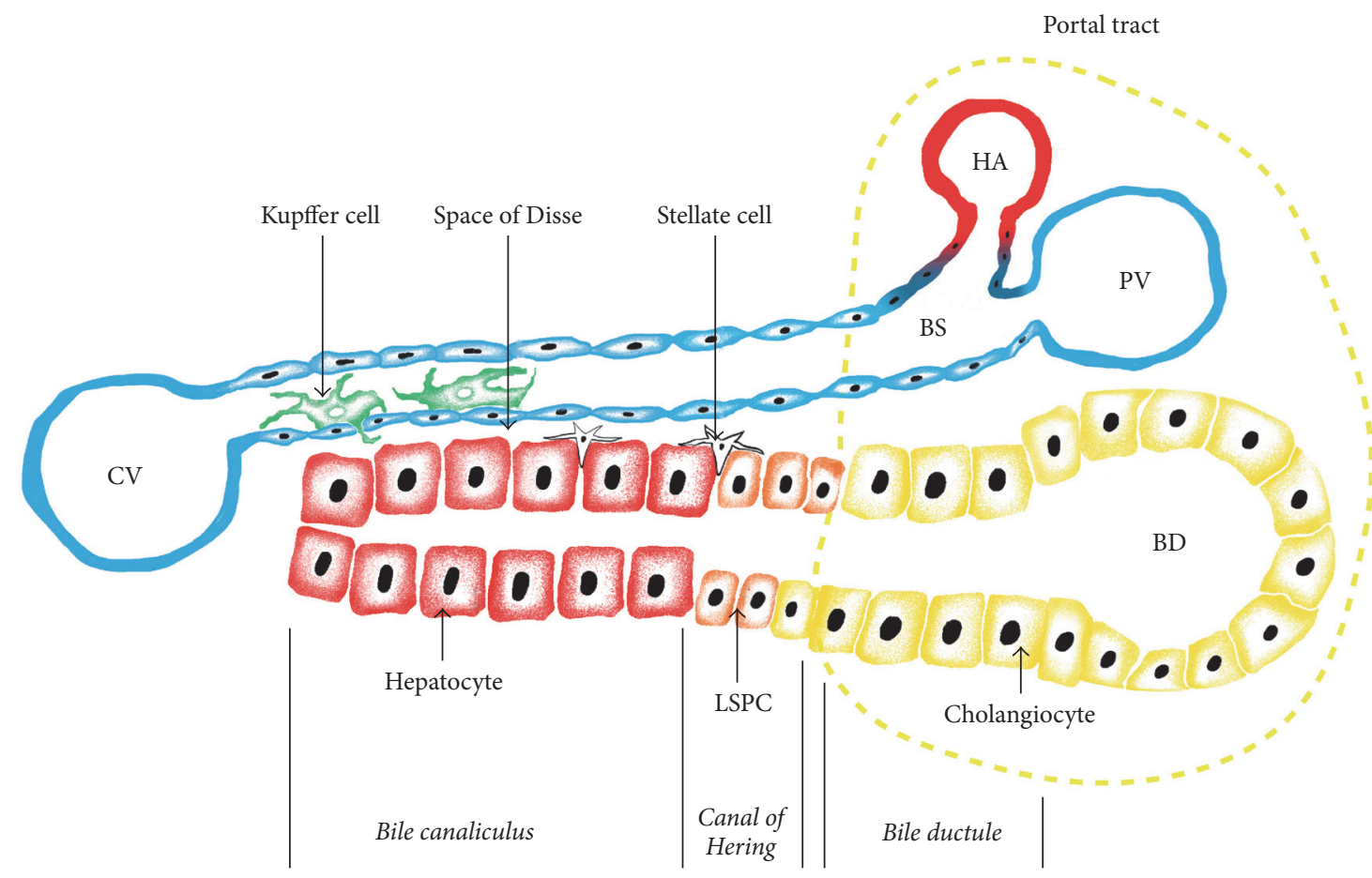

FIGURE 1: Schematic histological structure of liver tissue. Functional units of liver tissue are formed by trabeculae and accompanying blood sinusoids. Liver tissue gets its afferent blood supply from two sources: hepatic artery and portal vein. Hepatic arterioles (HAs) and the terminal branches of portal vein (PV) merge to form blood sinusoids (BSs) lined with endotheliocytes and drained into the central veins (CVs). In the sinusoids, close to endothelium reside liver macrophages named Kupffer cells. Bile produced by hepatocytes flows in the opposite direction and is discharged into the bile ducts (BDs). Hepatic arterioles, terminal branches of portal vein, and the smallest bile ducts are drawn together forming compact structures called portal tracts shown at the right side of the figure. Liver trabeculae are built of hepatocytes. The inner cavities of trabeculae form canaliculi which are closed at the central ends of the lobules (left side of figure) and while on their way to BD they convert into bile ductules (BDLs) via a transitory zone called the canals of Hering $(\mathrm{CH})$. Bile ductules drained into the bile ducts are lined with cholangiocytes, and the canals of Hering contain LSPCs. Tiny spaces between trabeculae and the endothelium of blood sinusoids are called the spaces of Disse (SD). They participate in the bidirectional traffic of different substances between blood and hepatocytes and contain stellate (Ito) cells.

and the transplanted one) grow to restore normal organ size to serve both individuals [22].

Regenerative response to partial hepatectomy involves numerous coordinated events occurring at the molecular, cellular, and tissue levels. In mice and rats the removal of three liver lobes leads to immediate changes of hepatocyte gene expression pattern, activation of numerous transcription factors and receptors, and secretion of a number of growth promoting signal molecules into liver parenchyma and circulation $[23,24]$. Apparently, liver regeneration after partial hepatectomy is a result of hepatocyte proliferation and hypertrophy but does not involve proliferation and hepatogenic differentiation of LSPCs [21, 23]. Liver regeneration combines hepatocyte hypertrophy and hyperplasia. Hepatocyte hypertrophy starts within hours after partial hepatectomy and is followed by hepatocyte hyperplasia. Full functional restoration after injury should involve restitution of all functions of normal liver including control of blood sugar levels, production of albumin, blood clotting factors and other vital proteins, bile secretion, and neutralization of poisonous substances. In rodents, time required for functional restoration depends upon experimental conditions. In humans, among factors affecting restoration time most are the extent of liver damage, diseases of liver parenchyma, age, and portal pressure [25-27].

In rat and mouse models, DNA synthesis begins 12-16 hours after partial hepatectomy and reaches its maximum after 24-48 hours [21]. The initial mass of liver is restored in about 3-7 days. At this stage the histology of regenerated liver tissue is still very different from normal, hepatocyte propagation slows down, and new blood vessel formation begins [21]. Ito cells secrete beta platelet-derived growth factor $(\beta$ PDGFR), thus contributing to hepatocyte proliferation arrest [28]. Normal liver histology and functions are restored within 8-10 days.

The relative input of hepatocyte proliferation and hypertrophy in liver size restoration after partial hepatectomy has been extensively studied. If there were no hypertrophy, it would take around 1.6 divisions of an average hepatocyte to regain the organ size after removal of $70 \%$ of its mass. However, hypertrophy of hepatocytes after partial hepatectomy is well documented, and it is well known that there are many binuclear hepatocytes in adult liver and their number decreases during posttraumatic regeneration [29, 30]. Using a specially developed method of cell size and ploidy determination, Miyaoka et al. [31] showed that in 
mice cellular hypertrophy makes the first contribution to liver mass restoration. In their experiments regeneration after removal of $30 \%$ of liver was achieved solely by hypertrophy without cell division, while after $70 \%$ hepatectomy hypertrophy preceded proliferation. Some of the hepatocytes were undergoing mitosis without cytokinesis and remained binuclear and diploid.

While the crucial role of hepatocyte proliferation and polyploidy in partial hepatectomy-induced regeneration has been repeatedly confirmed, the origin of new hepatocytes in regenerating liver is still a matter of discussion. It has been suggested that some of them descend not from other hepatocytes but from LSPCs or even from bloodborne cells. Early publications provided evidence supporting the predominant role of differentiated hepatocytes, while later many researchers were supporting the "streaming liver hypothesis" claiming constant proliferation of LSPCs during liver homeostasis and after enhancement of the regeneration process after injury [32]. However, other researchers applying improved methods of genetic cell lineage tracing provided additional evidence confirming the crucial role of proliferation of differentiated hepatocytes in homeostatic conditions and after partial hepatectomy. Malato et al. [33] designed an approach ensuring stable expression of the enhanced yellow fluorescent protein in adult murine hepatocytes, making it possible to trace the fate of cells over a period of time. This approach delivered experimental data proving that under normal homeostatic conditions adult differentiated hepatocytes are the source of all new hepatocytes. Moreover, the majority ( $99 \%)$ of new hepatocytes emerging during partial hepatectomy-induced regeneration also originate from differentiated hepatocytes. Therefore, hepatocytes may be regarded as committed unipotent cells reproducing themselves as suggested by Zhang et al. [34], while there seems to be no place remaining for LSPCs in homeostatic murine liver regeneration and its regeneration after partial hepatectomy. Data concerning the relative impact of hepatocytes and LSPCs in liver regeneration after other types of hepatic injuries will be analyzed in the following section.

Initiation of regeneration after partial hepatectomy may be associated with hemodynamic changes. Surgical removal of two-thirds of liver results in approximately threefold increase of portal pressure [35]. This induces proliferation of several liver cell types: hepatocytes, stellate cells, bile duct epithelium, hepatic macrophages (Kupffer cells), and fenestrated endothelium of vascular sinusoids. Hepatocytes are the first cell type starting DNA synthesis after partial hepatectomy. Hepatocytes remaining in place after the removal of two-thirds of liver undergo one cycle of DNA synthesis yielding reconstitution of $60 \%$ of hepatocyte mass [36]. A fraction of hepatocytes enters additional rounds of DNA synthesis ensuring full recovery of liver parenchyma. There is an increase of the number of apoptotic cells at the end of DNA synthesis period reflecting correction of excessive regenerative response [37]. Hepatocyte proliferation starts at portal areas containing a portal vein, a hepatic artery, and a bile duct and proceeds in the direction of the central vein $[38,39]$. Hepatocytes surrounding the central vein are the last to replicate [40]. Proliferation of bile duct epithelium starts later than hepatocyte proliferation. It begins at days 2-3 and ends at days 4-5 after partial hepatectomy [40]. The timing of hepatocyte mitosis during liver regeneration is controlled by circadian clock [41, 42]. Some authors found as many as four waves of hepatocyte replication [42].

Compared to other organs, liver contains elevated numbers of resident macrophages (Kupffer cells). Meijer et al. [43] demonstrated the participation of Kupffer cells and migrating monocyte-derived macrophages in liver regeneration after partial hepatectomy. Liposomal clodronateinduced macrophage ablation resulted in slowing down induced hepatocyte proliferation and, as a result, liver inability to fully restore its mass, suggesting an important role of macrophages-produced cytokines and growth factors in the initiation of hepatocyte proliferation. Wnt ligands are probably most critical for switching on hepatocyte proliferation $[44,45]$.

It should be stressed that microenvironment including cells and extracellular matrix plays a substantial role in the maintenance of liver tissue homeostasis and in regenerative response [23, 46]. Ding et al. [47] proved an important role of endothelium in hepatocyte proliferation support and reconstruction of vascular net in the regenerating liver.

\section{Evidence for and against the Existence of Alternative, LSPCs-Dependent Mechanisms of Liver Regeneration}

During the last three decades growing number of publications described liver regeneration mechanisms activated in case of hepatocyte proliferation blockage. Here we call those mechanisms "alternative" in order to stress their distinction from "classical" regeneration mechanisms implicated in liver regrowth after partial hepatectomy and involving compensatory hypertrophy and hyperplasia of hepatocytes. Instead of adult hepatocytes, alternate liver regeneration mechanisms are supposed to involve LSPCs capable of differentiation into hepatocytes, oval cells (considered LSPCs by many researchers), and, to a lesser extent, Ito (stellate) cells [48].

Historically, rat oval cells were the first described liver cell type with stem/progenitor properties. It has been shown that partial hepatectomy combined with DNA damage results in proliferation of certain cells in the terminal branches of the biliary tree [49]. Lineage tracing with ${ }^{3} \mathrm{H}$-thymidine indicated that these propagating "oval cells" can undergo hepatogenic differentiation thus participating in the replenishment of liver parenchyma. From the very start there were two competing point of views-one regarding oval cells as hepatogenic progenitors and the other claiming that oval cells are dedifferentiated hepatocytes. Partisans of the first point of view maintained that oval cells serve as an emergency tissue compartment providing material for restoration of liver parenchymal cells and can be regarded as LSPCs. Really, it was demonstrated that in rodents a number of hepatic poisons including dipin, retrorsine, or galactosamine reduce the replicative activity of the majority of hepatocytes and induce oval cells to propagate and regrow liver parenchyma $[50,51]$. In humans, acute liver damage or chronic liver disease, such as late stage cirrhosis, provokes activation 
of progenitor cells [52]. Like oval cells, human progenitor cells or LSPCs reside in the canals of Hering $[53,54]$. A clinical study carried out with biopsies taken from patients with massive hepatic necrosis occurring after partial liver transplantation demonstrated the crucial role of LSPCs in the parenchyma regrowth after acute liver failure [55]. Significant role of LSPCs in liver regeneration got further experimental and clinical support. For instance, positive outcomes after acetaminophen-induced liver damage seem to be directly correlated with serum alfa-fetoprotein level [56]. Since alfafetoprotein is produced mainly by resident progenitor cells, its enhanced production may reflect their active proliferation. Clinical significance of LSPC propagation in late stage cirrhosis patients is obscured by the lack of restoration of hepatocyte numbers and functional recovery $[57,58]$. In this case weak proliferation of LSPCs was ascribed to hepatocyte replicative senescence and exhaustion of their proliferative potential.

At present, the concept of LSPC-dependent liver regeneration mechanisms lives on almost in its original form insisting that LSPCs residing in the terminal branches of biliary tree become a major source of newly generated parenchymal cells when standard hepatocyte-dependent regeneration is compromised due to irreversible hepatocyte damage [59]. Conversely, in case of biliary epithelial cells failure to proliferate hepatocytes turns out to be the source of facultative stem/progenitor cells for biliary epithelium. It has been claimed that LSPCs possess high proliferative potential, express bile duct epithelial cell markers, and are able to differentiate into both hepatocytes and bile duct epithelial cells in vitro (reviewed in [60]). However, no specific LSPC markers were detected as yet. LSPC differentiation seems to be driven by the activity of certain genes and a unique combination of growth factors. Crucially important genes include Leucine-rich repeat-containing G-protein coupled receptor 5 (LGR5) [61, 62] and the cytokine tumor necrosis factor-like weak inducer of apoptosis (TWEAK), a member of the tumor necrosis factor (TNF) superfamily [63]. In addition, significant role belongs to known mitogenic factors, such as HGF, epidermal growth factor (EGF), TGF- $\alpha$, and fibroblast growth factors 1 and 2 (FGF1 and FGF2) $[64,65]$.

In normal human liver cells displaying mixed biliary epithelium/hepatocyte differentiation potential are found in distal parts of the canals of Hering where bile duct epithelium is in close proximity of hepatocytes [66]. Studies in rats and mice reported transdifferentiation of hepatocytes into bile duct epithelial cells under circumstances preventing renewal of the biliary epithelium [67-69]. Most probably, this process involves periportal hepatocytes, a distinct subpopulation of hepatocytes originating from the ductal plate [70,71]. During embryogenesis both hepatocytes and cholangiocytes descend from common precursor cells known as hepatoblasts. Separation of the hepatocyte and cholangiocyte lineages occurs rather late in rodent embryogenesis and in the middle of the second trimester in humans [72-74]. Therefore, transdifferentiation of bile duct cells into hepatocytes and vice versa really looks quite natural and those two liver cell types are likely to operate as each other's conditional stem/progenitor cells $[59,67]$. In humans this mechanism of regeneration is probably activated in fulminant liver failure. In fulminant hepatitis the histological examination of liver tissue reveals clusters of parenchyma regeneration consisting of cells displaying features of differentiation into both hepatocytes and cholangiocytes. In addition, in most cases there is a vast proliferation of bile duct cells starting to express hepatocyte biomarkers [74-76]. Clinical data, as well as the results of the model experiments with laboratory rodents, suggest that in fulminant liver failure hepatocytes are regenerated through cholangiocyte transdifferentiation [59].

All these and many other results accumulated over the years are entirely consistent with the idea of facultative LSPCs serving as a source of hepatocytes after certain hepatic injuries. However, the concept of LSPCs playing a substantial role in liver regeneration was almost destroyed by several papers published in 2014. Four research groups applied innovative lineage tracing methods to determine progenitors of new hepatocytes emerging in the course of regeneration in standard murine liver damage models. Schaub and coauthors [77] using cytokeratin-19 (CK19) lineage tracing for LSPC progeny and high-efficiency hepatocyte marking demonstrated that, in the model of chronic liver injury caused by a special choline-deficient, ethionine-supplemented (CDE) diet regeneration did not involve LSPCs and all new hepatocytes stemmed from hepatocytes. Cell fate tracing utilizing of stellate (Ito) cell progeny in Pdgfrb-cre mice demonstrated that no hepatocytes emerged from those cells as well. This evidence was in line with data presented by Yanger and coauthors [78] showing that independent of the kind of injury preexisting hepatocytes and not LSPCs or oval cells are the main if not the only source of hepatocytes newly generated during adult liver regeneration. The experiments were carried out using four different mouse oval cell injury regimens and three distinct methodological approaches. The first method based on the usage of a bile-duct-specific, tamoxifen-inducible creline failed to demonstrate any CK19-marked hepatocytes in any of four injury models. High-efficiency labeling of differentiated hepatocytes combined with oval cell damage and subsequent quantification of unlabeled hepatocytes (2nd method) gave no sign of LSPCs different from hepatocytes. Finally, the third method using nucleoside analogs to track rapidly dividing cells showed no rapidly proliferating oval cells undergoing hepatogenic differentiation. Furthermore, cell fate studies in mice employing biliary cell tracers $\mathrm{Hnfl} \beta$ [79] and ductal transcription factor Sox9 [80] also demonstrated negligible involvement of oval cells/LPSCs in postinjury liver regeneration. Together, four described publications established primary role of hepatocytes in homeostatic and especially postinjury liver self-renewal and strongly argued against participation of oval cells/LSPCs in liver parenchyma renewal or replenishment. Hepatocytes were shown to be able to replicate even in case of very severe liver damage. Soon afterwards it was shown that in a mouse chronic liver damage model new hepatocytes originated from the so-called hybrid hepatocytes, a subpopulation of periportal hepatocytes present in intact liver and capable of rapid proliferation [81]. Hybrid hepatocytes are characterized by low level of Sox9 expression and normal expression of hepatocyte nuclear factor $4 \alpha$ (HNF $4 \alpha)$. They express genes specific for hepatocytes and some cholangiocyte-specific genes. 
The described lineage tracing experiments clearly changed the previously adopted model of liver regeneration. However, there are doubts concerning generalization of those findings. Accurate cell fate experiments were performed only in mice and it is not yet clear if other species, including rats and humans, also lack LSPCs with in vivo hepatocytereplenishing capacity. Besides, despite lack of the proof of the in vivo hepatogenic differentiation of LSPCs, they certainly can give rise to hepatocyte-like cells in vitro [48]. Research in this field is ongoing and there is a chance that even in mice a role for oval cells/LSPCs in regeneration will be found. Recently, CD45-TER119-CD31-EpCAM-ICAM-1+ resident progenitor cells, distinct from conventional oval cell-like LSPCs, were described [82]. Those cells were first found in late murine fetuses and postnatal puppies, reach peak numbers by the 4 th week after birth, and persist throughout life. They were shown to differentiate into mature hepatocytes in vitro. Upon transplantation they participate in the recipient's liver repopulation after partial hepatectomy combined with retrorsine treatment or after treatment with oncostatin M. They also contribute to cellular turnover in normal healthy mouse liver, that is, participate in homeostatic organ regeneration.

\section{Involvement of Extrahepatic Stem/Progenitor Cells in Liver Regeneration}

Certain extrahepatic cells including hematopoietic stem cells (HSCs) and mesenchymal stem cells (MSCs) of bone marrow origin can be induced to differentiate into liver cells in vitro. There are several lines of evidence suggesting that differentiation of bone marrow HSC or MSC into cells of hepatic lineages may also occur in vivo in physiological conditions and after liver injury. Bone marrow HSC and MSC can easily reach liver through circulation. In embryogenesis the hematopoietic system and liver closely interact [83]. Fetal liver is an important source of HSC [84]. Moreover, HSCs persist in liver tissue throughout adulthood [85]. HSCs were shown to undergo hepatogenic differentiation and to populate liver after intravenous transplantation [34, 86, 87]. Similar data were reported by research groups working with MSC, another major bone marrow stem cell type [34, 88, 89] (Table 1).

It has been noticed that oval cells of adult liver express Thy-1, a surface marker routinely used together with CD34 to specifically identify HSC [90]. Hepatocyte proliferation blocker 2-acethylaminofluorene combined with liver injury to induce oval cell proliferation in rats after cross-sex bone marrow transplantation induced appearance of oval cells bearing the transplanted bone marrow genetic marker, $\mathrm{Y}$ chromosome [90]. In a similar study, female mice after cross-sex bone marrow transplantation obtained over $2 \%$ hepatocytes with Y chromosome [91]. Interestingly, relatively high levels of liver repopulation with donor-derived hepatocytes in the cited reports were attributed to the blockage of resident hepatocyte proliferation with irradiation [92]. It was reported that in mice HSC represent the main if not unique type of liver-repopulating bone marrow cells [86]. Therefore, data from animal experiments suggest the possibility of participation of HSC and probably other bone marrow cells in liver regeneration. The extent of their participation in humans remains obscure. However, circumstantial evidence suggests that it can take place and play a role in regeneration $[14,91]$. Interpretation of experimental and clinical data in this field is difficult, because of the complexity of the involved cellular mechanisms. Some researchers failed to find the proof of participation of bone marrow cells in hepatocyte generation in the course of mouse liver regeneration after partial hepatectomy [93]. Bone marrow-derived hepatocytes usually constitute less than $1 \%$ of total hepatocyte population of transplanted human liver and sometimes are not present at all (data reviewed in [23]).

It has been established that only a fraction of HSC participates in hepatocyte replenishment. Initially, it was shown that in a FAH-/- (fumarylacetoacetate hydrolase-deficient) mouse model only (c-Kit ${ }^{\text {high }}$ Thy ${ }^{\text {low }}$ Lin-Scal+)-HSC, but not c-Kit-Scal- or lineage-positive ( $\mathrm{Lin}+$ ) cells, differentiated into hepatocyte-like cells [86]. Other research groups either confirmed these results or determined different HSC phenotypes [94, 95]. In a recent publication $\mathrm{Oh}$ et al. [96] reported isolation of endodermal precursor cells from the subpopulation of Lin-Sca1+ cells of murine HSC. Only those endodermal precursor cells participated in liver repopulation with hepatocytes in two models of liver damage. This finding is in accordance with the suggestion that bone marrow contains multipotent precursors of the parenchymal cells of different tissues [97].

It has been proposed that bone marrow-derived hepatocytes are generated by the fusion of HSC with liver hepatocytes rather than by direct transdifferentiation of HSC into hepatocytes $[98,99]$. Though this hypothesis has been disputed [94], it is still getting support in some recent publications. Using fumarylacetoacetate hydrolase-deficient (FAH-/-) mice as a model of liver failure, Li et al. [100] demonstrated that bone marrow-derived hepatocytes can be generated by fusion of BM-derived CD11b+F4/80+ myelomonocytes with resident $\mathrm{FAH}-/-$ hepatocytes.

As suggested by Prockop [12], bone marrow MSCs provide a pool of stem cells for nonhematopoietic tissues including liver tissue. Like HSC, MSCs are a very heterogeneous cell population. It has been shown that only a tiny fraction of bone marrow MSC, the so-called multilineagedifferentiating stress-enduring (Muse) cells, participate in liver regeneration [101]. After injection of green fluorescent protein-labeled human bone marrow Muse cells into partially hepatectomized immunodeficient mice, immunohistochemistry, in situ hybridization, and species-specific polymerase chain reaction revealed their integration into the liver tissue during the early regeneration phase [102]. Integrated human cells expressed liver progenitor markers and afterwards differentiated into the following liver cell types: hepatocytes $(\approx 74.3 \%$ of GFP-positive integrated Muse cells), cholangiocytes $(\approx 17.7 \%)$, sinusoidal endothelial cells $(\approx 2.0 \%)$, and Kupffer cells $(\approx 6.0 \%)$. These data correlated with the results of genotyping of 20 human liver transplants by short tandem repeats which revealed the presence of recipient or chimeric genotypes in hepatocytes (6 of 17, $35.3 \%$ ), sinusoidal cells (18 of 18, 100\%), cholangiocytes (15 
TABLE 1: Role of various cells in liver regeneration.

\begin{tabular}{|c|c|c|c|}
\hline Type of cells & Animal model & $\begin{array}{l}\text { Examples of similar human disease or } \\
\text { state }\end{array}$ & Cellular mechanisms involved \\
\hline $\begin{array}{l}\text { Differentiated } \\
\text { hepatocytes }\end{array}$ & $\begin{array}{l}\text { Homeostatic regeneration, } \\
\text { partial hepatectomy (rat, mouse), } \\
\text { choline-deficient, } \\
\text { ethionine-supplemented (CDE) } \\
\text { diet (mouse), chronic CCl4 } \\
\text { (mouse), } \\
\text { diethyldithiocarbamate- (DDC-) } \\
\text { induced liver damage (mouse), } \\
\alpha \text {-naphthylisothiocyanate- } \\
\text { (ANIT-) induced liver damage } \\
\text { (mouse) }\end{array}$ & $\begin{array}{l}\text { Homeostatic regeneration, partial liver } \\
\text { resection (cancer, bleeding after } \\
\text { mechanical trauma, etc.), organ mass } \\
\text { restoration after partial liver } \\
\text { transplantation, liver fibrosis and } \\
\text { cirrhosis, acute or chronic liver failure }\end{array}$ & $\begin{array}{l}\text { Hypertrophy followed by hyperplasia } \\
\text { and differentiation into hepatocytes or } \\
\text { transdifferentiation into } \\
\text { cholangiocytes; debated if all or a } \\
\text { subpopulation (e.g., hybrid periportal } \\
\text { hepatocytes) of hepatocytes participate }\end{array}$ \\
\hline LSPCs & $\begin{array}{l}\text { Liver poisoning by dipin, } \\
\text { retrorsine, galactosamine (rat, } \\
\text { mouse), CDE diet (mouse), } \\
\text { chronic CCl4 (mouse), } \\
\text { DDC-induced liver damage } \\
\text { (mouse), ANIT-induced liver } \\
\text { damage (mouse), and so forth }\end{array}$ & $\begin{array}{l}\text { Acute or chronic liver failure, } \\
\text { including liver tissue necrosis after } \\
\text { poisoning or partial liver } \\
\text { transplantation }\end{array}$ & $\begin{array}{l}\text { Expansion and differentiation into } \\
\text { hepatocytes, cholangiocytes, and } \\
\text { probably other liver cell types; debated } \\
\text { if this mechanism of liver regeneration } \\
\text { exists }\end{array}$ \\
\hline Blood-borne HSCs & $\begin{array}{l}\text { Hepatocyte proliferation } \\
\text { blockade combined with liver } \\
\text { injury to induce oval cell } \\
\text { proliferation after cross-sex bone } \\
\text { marrow transplantation (rat, } \\
\text { mouse, pig) }\end{array}$ & $\begin{array}{l}\text { Any disease or state; liver } \\
\text { transplantation }\end{array}$ & $\begin{array}{l}\text { Transdifferentiation into hepatocytes; } \\
\text { after liver transplantation } \\
\text { transdifferentiated HSCs substitute } \\
\text { donor hepatocytes; debated what } \\
\text { subpopulation of HSCs ("endodermal } \\
\text { progenitors," multipotent precursors) } \\
\text { participate; dusion with resident } \\
\text { hepatocytes (?) }\end{array}$ \\
\hline Blood-borne MSCs & $\begin{array}{l}\text { Transplantation of human MSCs } \\
\text { into immunodeficient partially } \\
\text { hepatectomized } \\
\text { immunodeficient mice, } \\
\text { hepatocyte proliferation } \\
\text { blockade combined with liver } \\
\text { injury to induce oval cell } \\
\text { proliferation after cross-sex bone } \\
\text { marrow transplantation (rat, } \\
\text { mouse, pig) }\end{array}$ & $\begin{array}{l}\text { Any disease or state; liver } \\
\text { transplantation }\end{array}$ & $\begin{array}{l}\text { Transdifferentiation into hepatocytes } \\
\text { and other liver cell types; after liver } \\
\text { transplantation transdifferentiated } \\
\text { MSCs substitute donor hepatocytes; } \\
\text { debated what subpopulation of MSCs } \\
\text { (Muse cells or others) participate; } \\
\text { fusion with resident hepatocytes (?) }\end{array}$ \\
\hline
\end{tabular}

of $17,88.2 \%)$, and cells in the periportal areas (7 of $8,87.5 \%)$ [102].

Other research groups characterized different bone marrow MSC culture subpopulations capable of multilineage differentiation, including the so-called multipotent adult progenitor cells [103] and very small embryonic-like stem cells [104]. Still different subpopulations able to differentiate into liver cells and other endoderm derivatives were found in MSC isolated from other sources.

It is noteworthy that bone marrow cells participate in the regeneration of liver endothelium. Endothelial cells of bone marrow origin can comprise more than $20 \%$ of replenished liver endothelial cells after liver transplantation in humans or after partial hepatectomy in rodents [93].

Data concerning the participation of the blood-borne bone marrow cells in the regeneration of liver parenchyma are of prime importance for the development of cell and the methods of cell therapy of liver diseases.

\section{Cell-Based Technologies in Hepatology}

Most conventional approaches of modern medicine help to alleviate disease symptoms by repairing biochemical or anatomical abnormalities or substituting missing and damaged parts with prostheses. They do not attempt to mobilize the curative capacities of the patient's own body. Regenerative medicine is a rapidly developing discipline specifically addressing this issue [105]. Regenerative medicine also attempts to directly repopulate damaged tissues with transplanted cells and to substitute malfunctioning organs using tissue/organ engineering techniques. Application of the methods of regenerative medicine in hepatology holds promise to deliver beneficial outcomes surpassing those provided by other therapeutic approaches $[106,107]$.

At present, the majority of the technologies of regenerative medicine are based on the use of live cells. Other tactics, such as stimulation of regeneration with medicines [108] or usage of the components of cell secretome instead 


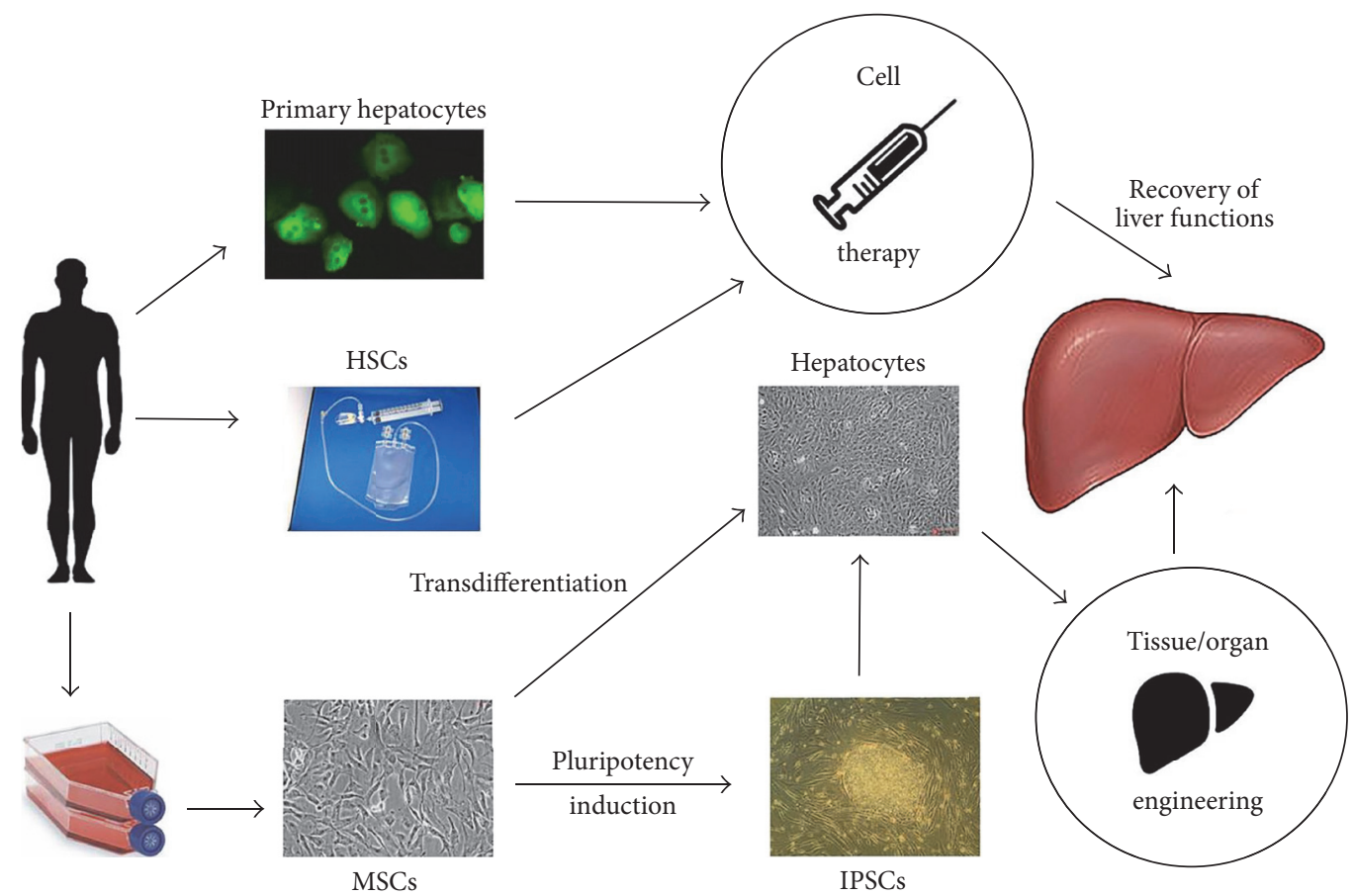

FIGURE 2: Methods of regenerative medicine for the therapy of liver diseases. Hepatocytes, hematopoietic stem cells (HSCs), and mesenchymal stromal cells (MSCs) are the three cell types commonly used as starting material for the design of cell-based therapies of liver diseases and for liver tissue/organ engineering. Primary hepatocytes isolated from liver biopsies and HSCs isolated from bone marrow or blood, are used for cell therapy after minimum in vitro processing. HSCs can be also expanded in culture (not shown) before transplantation or induced to pluripotency and utilized in cell therapy and tissue/organ engineering applications after hepatogenic differentiation. Chances are that HSCs can be directly transdifferentiated into hepatocytes. MSCs after isolation are in most cases extensively expanded. MSC cultures are then either used for transplantation or transformed into hepatocytes or other liver cells via iPSCs or by direct transdifferentiation. MSC-derived differentiated liver cells are used in cell therapy and tissue/organ engineering applications.

of whole intact cells [109], are just emerging. There are two basic approaches to clinical application of cell-based technologies in hepatology: cell therapy and tissue/organ engineering. Both are at early stages of their development and much more preclinical and clinical research is needed before efficient and safe therapies will be available. In addition, present day regenerative hepatology only partly relies on the achievements in basic liver regeneration research. However, huge investment of effort and resources taking place at present makes ultimate success quite likely.

Cell therapy involves transplantation of the suspensions of cells via different routes, most commonly intravenously. It is a relatively inexpensive method with a potential to provide excellent results in some cases. The rationale of cell therapy of liver diseases is twofold. First, some cells, such as autologous hepatocytes, can directly repopulate damaged liver tissue. It is also possible that certain types of cells can transdifferentiate into liver cells after homing within liver tissue. Second, transplanted cells produce beneficial effects, such as stimulation of tissue regeneration, by paracrine secretion of balanced combinations of cytokines, chemokines, growth factors, and noncoding RNAs affecting resident progenitors, extrahepatic stem cells, and other targets (Figure 2).

Tissue/organ engineering encompasses ex vivo assembly of liver tissue, a liver lobe, or whole liver with subsequent orthotopic implantation. Tissue/organ engineering can include a transitory stage of heterotopic implantation of tissue and its growth in vivo. Liver tissue/organ engineering using autologous or allogeneic cells can solve the problem of donor liver shortage. Engineering of whole human liver or its lobe is not just a very challenging but also a very expensive enterprise. The latter is particularly true in case of engineering of an immune conflict-safe liver from autologous cells. Fortunately, recent scientific developments offer clues for scaling up the tissue/organ manufacturing process by the use of immunologically neutral allogeneic cells. In this case organs intended for transplantation can be manufactured using relatively cheap large scale industrial technologies.

6.1. Cell Therapy with Hepatocytes. Since compensatory hyperplasia of differentiated adult hepatocytes is the principal way of liver regeneration after injury, repopulation of damaged liver tissue with transplanted hepatocytes or their progeny looks logical. Transplantation of primary (noncultivated) hepatocytes via portal vein proved effective in some animal liver disease models (reviewed in $[110,111]$ ) and treatment of human liver metabolic and genetic disorders like hepatolenticular degeneration (Wilson-Konovalov disease), tyrosinemia, Crigler-Najjar syndrome, urea cycle disorders, severe dyslipidemia, and others (reviewed in $[112,113]$ ). Though homing within liver tissue and participation in its repopulation are thought to be the main mechanism 
underlying the effects of primary hepatocytes transplantation, stimulation of tissue regeneration through paracrine action is also involved. Unfortunately, accumulated clinical experience is insufficient to define the optimum quantity of infused cells and number of transplantations and intervals between transplantations, as well as the extent and duration of immunosuppression needed. Moreover, transplantation of human primary hepatocytes had virtually no effect in acute liver failure or chronic liver disease [114, 115]. Because of drastic shortage of donor organs, human hepatocytes intended for cell therapy are harvested from livers unsuitable for organ transplantation and, accordingly, are inferior in quality. For that reason, uncertain efficacy or lack of efficacy of primary human hepatocytes transplantation is probably due to poor quality of infused cells.

There were attempts to use primary fetal hepatocytes or hepatoma cell lines instead of adult primary hepatocytes [114, 115]. Cell therapy utilizing those kinds of primary hepatocytelike cells showed limited efficacy probably because of limited functionality of immature transplanted cells. In addition, fetal material can cause formation of teratomas, while transformed cell lines are thought to have oncogenic potential. A number of research groups reported effective engraftment of xenogeneic hepatocytes into the liver tissue and suggested transplantation of porcine hepatocytes into humans [116, 117]. However, due to safety concerns this option will have hard time getting through the regulation hurdles.

Despite many difficulties, further attempts to improve the methods of ex vivo expansion of human hepatocytes isolated from adult livers, while preserving their metabolic functions, engraftment properties, and in vivo proliferation potential are underway. There is progress in inventing approaches to viable hepatocytes extraction from cadaveric [118] and steatotic [119] livers by adding antioxidants and other beneficial supplements to the perfusion solution. Recently, Levy et al. [120] reported successful oncostatin $\mathrm{M}$-dependent expansion of primary human hepatocytes by inducing low expression of the human papilloma virus genes E6 and E7 coupled with inhibition of epithelial-to-mesenchymal transition. Huch et al. [121] showed that adult bile duct-derived bipotent progenitor cells from human liver can be expanded as epithelial organoids in vitro and then differentiated into functional hepatocytes in vitro and in vivo.

Luckily, progress in cell biology offers new opportunities and alternative ways to generate human hepatocytes, including allogeneic hepatocytes for immunosuppressionfree transplantation. Reprogramming of somatic cells into induced pluripotent stem cells (iPSCs) introduced by Yamanaka group [122] presented a unique opportunity to obtain autologous pluripotent cells for cell therapy and tissue engineering. These cells are pluripotent cells similar to embryonic stem cells and can be converted into any differentiated cell type using methods similar to those developed for embryonic stem cells. Reports of successful hepatogenic differentiation of human iPSCs carried out in three or four stages [123-125] were published soon after introduction of the technology of pluripotency induction. Production of hepatocytes via iPSC stage has been successfully scaled up $[126,127]$. Methods of large scale production of immunologically neutral allogeneic human hepatocytes from iPSCs will be described in more detail further, in the Liver Organ/Tissue Engineering.

In vitro hepatogenic differentiation of iPSCs yields just partially differentiated hepatocyte-like cells. To undergo full differentiation they need proper microenvironment which is difficult to reproduce ex vivo. However, transplanted cells are likely to get all necessary environmental differentiation stimuli after homing in liver tissue.

6.2. Cell Therapy with Liver Stem/Progenitor Cells. After hepatocytes, LSPCs appear to be the most convenient candidates among all liver cell types for restoration of the organ parenchyma and tissue engineering. Indeed, the ability of LSPCs to differentiate into hepatocytes and bile duct cells in vitro has been well documented (reviewed in [60]). Accordingly, it is likely that after transplantation part of LSPCs will undergo homing in the recipient's liver and differentiate into hepatocytes and bile duct cells. Successful in vitro expansion of mouse [61] or rat [128] LSPCs, their engraftment into the liver tissue, and hepatogenic differentiation after transplantation were reported. Efficient expansion of human LSPCs in culture was described as well [62]. Further research is necessary to clarify LSPCs' curative potential.

Liver tissue response to different stimuli and to damage includes orchestrated reaction of all resident cell types. Efficacy of the methods of cell therapy in hepatology will improve parallel to increase of our knowledge about the complexity of interactions of different liver tissue compartments.

6.3. Cell Therapy with Hematopoietic Stem Cells. Liver is the site of homing of cells of extrahepatic origin, such as HSCs, stromal cells, and immune cells, suggesting a role for bloodborne cells, including stem cells, in liver regeneration. The next two sections are devoted to cell therapy with HSCs and MSCs.

The scientific basis for cell therapy of liver diseases with HSC transplantation is twofold. First, blood-borne bone marrow-derived HSCs allegedly participate in liver regeneration $[8,86,129]$. Second, in animal models of liver malfunction infusion of HSC improves the outcomes [34, 86, 87]. Therapy with macrophages differentiating from HSCs improves outcomes of liver fibrosis in mice [130]. It has been established that transplantation of hematopoietic cells [131] or their derivatives such as macrophages (analyzed in [132]) alleviates symptoms of human liver diseases as well. The extent of substitution of lost or damaged hepatocytes by differentiating HSC does not exceed 1-2\% of newly emerged hepatocytes [129], suggesting that liver tissue regeneration and repopulation after HSCs infusion are essentially induced through paracrine action of transplanted cells. It is possible, though, that the proportion of new hepatocytes differentiating from HSCs can be increased by using the subpopulation of pluripotent cells present in the bone marrow HSC population [94-97]. However, because of the danger of teratoma formation, more animal research is needed before human tests are allowed.

HSC transplantation, especially repeated procedures, can cause adverse immunological reactions and may require immunosuppressive therapy. Adverse effects can be avoided 
utilizing immunologically neutral allogeneic human cells from cord blood or prepared from iPSCs as described in the Liver Engineering.

6.4. Cell Therapy with Mesenchymal Stem Cells. The rationale for MSC-based therapy is similar to that for HSC-based therapy. Prockop [12] was the first to suggest that bone marrow MSCs contain subpopulations of cells participating in regeneration of the parenchyma of different organs including liver. Later, several research groups reported isolation of cells capable of multilineage differentiation from bone marrow-derived MSC cultures, as well as MSC cultures isolated from other tissues. Cells characterized by each group proved to display somewhat unique properties and got different names. The following types of MSC subpopulations received most attention from the scientific community: "multipotent adult progenitor cells" (MAPC) [103], "very small embryonic-like stem cells" (VSEL cells) [104], and "multilineage-differentiating stress-enduring" (Muse) cells [101]. Cells of each of those types can be induced to differentiate not only into mesoderm, but also into ectoderm and endoderm derivatives and are able to home in the parenchyma of internal organs. Existing experimental and clinical data demonstrate considerable involvement of Muse cells in liver repopulation after injury $[101,102]$. Specifically, in immunocompromised mice, transplanted human Muse cells integrate into the liver tissue and differentiate in vivo into hepatocytes, cholangiocytes, sinusoidal endothelial cells, and Kupffer cells, producing human proteins [102].

In addition to being directly involved in repopulation of damaged liver tissue, MSCs are also able to stimulate regeneration via paracrine secretion (reviewed in $[133,134]$ ). In accordance with everything written above in this section, transplantation of MSC induces relief in animal models of liver pathology $[135,136]$ and in patients with liver problems [137, 138]. MSCs can induce beneficial changes in minor populations of liver cells. For example, in a murine liver fibrosis model MSCs are able to induce a profibrotic to resolutive phenotype shift in hepatic macrophages, which is a key early event promoting fibrosis reversion [139].

MSCs display a number of additional useful properties including low immunogenicity, affinity to the injury sites, and the ability to modulate immune responses $[134,140]$. They are also cheap in production. Unique MSC properties make them convenient cell material for the development of cell therapies, including cell therapies of liver diseases. For this reason the major part of preclinical and clinical research in the field of cell therapy of many human diseases is currently conducted with MSCs.

\section{Liver Organ/Tissue Engineering}

Orthotopic transplantation of allogeneic liver or its part is frequently the only life-saving option for patients with liver failure. Accordingly, reasonably priced and immune conflictfree donor liver substitutes are in urgent demand. There are chances that the problem of surrogate liver production can be solved by tissue engineering, an innovative strategy combining live cells with different natural and artificial materials to create transplantable functioning tissue or organ analogs (bioartificial grafts). While much more research is needed to adequately respond to organ transplantation challenges, bioengineered liver tissue is already used in drug metabolism studies [141].

Two liver engineering approaches have been experimentally checked to this point [142]. The first one involves repopulation of a decellularized liver stroma scaffold by hepatocytes, stem cells, endotheliocytes, and other cell types. Decellularization can be carried out by perfusion of the organ through its blood vessels with solutions containing enzymes and detergents [143]. It delivers an extracellular matrix scaffold free of cells and immunogenic proteins, reproducing in detail the architecture of liver stromal 3D backbone, offering support for repopulating cells and placing growing blood vessels and biliary ducts to their right positions. The ensuing scaffold can be recellularized in a bioreactor. In animal experiments repopulation of the scaffold can be carried out in vivo after heterotopic transplantation. Rat livers prepared utilizing decellularization/recellularization technology were successfully grafted into rats [144-146], while decellularized porcine liver scaffold populated with human cells was transplanted into a pig [147]. However, these and all subsequent publications reported grafted liver survival for less than a week underscoring the need for further technological improvements. Microencapsulation of hepatocytes before their engraftment into the tissue constructs facilitating long-time survival of functionally intact cells may be one of the useful improvements of the described technique [148].

Bioprinting is the second experimentally tested liver tissue engineering approach. Bioprinting combines 3D printing technology and biological materials including elements of extracellular matrix and live cells to form elaborate $3 \mathrm{D}$ tissue and organ structures, including vascular network. At present bioprinting already delivers metabolically active 3D hepatic tissue fragments which can be kept in a bioreactor alive and functioning for several days $[149,150]$.

Orthotopic transplantation of a recellularized liver graft to a patient with liver failure has not been performed yet and a number of problems need to be solved before clinical tests can be initiated. In addition to biotechnological issues, purely medical concerns, such as lack of a suitable surgical technique of orthotopic transplantation of engineered liver, need to be addressed. Choice of the cell material for liver engineering is also of great importance. As already indicated, autologous hepatocytes taken from patients with liver cirrhosis may be of poor quality. Allogeneic hepatocytes are difficult to get in large quantities and normally are immunologically incompatible with the graft recipient requiring life-long immunosuppression. Moreover, production of organs customized for each particular patient is a very costly and lengthy procedure. Recent basic research advances suggest the possibility of relatively cheap, essentially industrial production of organs for immunosuppression-free transplantation using immunologically matched allogeneic cells. The approach is based on the pluripotency induction technologies and the idea of the statistical prevalence of certain human leukocyte antigen (HLA) gene combinations within the population. 
Immortal iPSC lines can be prepared from the majority of differentiated cell types including such easily accessible cells as skin fibroblasts and CD34 fraction of blood-borne cells. Like embryonic stem cells, generated pluripotent cells can be differentiated into virtually any cell type, including hepatocytes and other liver cells $[107,151]$. Methods of hepatocytes production from iPSCs comprise several steps reproducing the stages of hepatocyte differentiation during ontogenesis. Three- and four-step protocols have been developed, each step guided by a specific set of growth and transcription factors. The four-step differentiation protocol was historically the first and included the stages of iPSC differentiation into the definitive endoderm, hepatocytic specification, hepatoblast expansion, and hepatocyte maturation [123]. Threestep protocols comprise consecutive iPSC differentiation into definitive endoderm, immature hepatocytes, and mature hepatocytes $[124,125]$. Hepatocytes derived from iPSC have metabolic and functional characteristics similar to primary human hepatocytes $[124,152]$ and retain basic hepatocyte properties in bioartificial liver microenvironments [153].

Except hepatocytes, liver tissue contains other cells necessary to ensure its functions. They all can be differentiated from iPSCs, and some of them can be differentiated from LSPCs. The ideal composition of cell cocktail for liver scaffold population or bioprinting is not known. There are many more problems to solve before transplantation of engineered liver constructs can proceed to the clinical testing phase and much more preclinical research is needed [154].

Customized engineering of liver for a particular patient is going to be very expensive and large scale production of organs from allogeneic cells is the only option realistic from the economic point of view. Immunological distinctiveness of individual people is determined by two coexpressed haplotypes, represented by HLA-A, HLA-B, and HLA-DR gene each. Importantly, there are statistically preferable patterns, because combinations of these three genes proved to be not random. It has been calculated that it is possible to select a limited number of HLA homozygous donors with statistically prevalent HLA gene patterns matching most of heterozygous potential cell and organ transplant recipients [155]. According to the calculations, 30 homozygous iPSC lines derived from donors selected from 15,000 Japanese individuals match $82.2 \%$ of potential Japanese recipients, while 50 lines from donors chosen from 24,000 people provide immunocompatible material to $90.7 \%$ of recipients. This finding provided the idea of national or global iPSC line registries [156-158]. Those registries could provide cellular material for immunosuppression-free cell therapy and tissue engineering. Cells can be produced in very large quantities, making them much cheaper.

Embryonic stem cells and iPSCs are undifferentiated pluripotent cells tailored to convert into various differentiated cells. As indicated in the Transplantation of MSCs, in vitro cultures of MSCs contain another kind of pluripotent cells that can be differentiated into hepatocytes. Since MSCs are cells of mesodermal origin, while hepatocytes belong to endodermal lineage, hepatogenic differentiation of a subpopulation of MSCs has been named "transdifferentiation." It is not yet clear if transdifferentiation of MSCs can yield fully functional hepatocytes, but research in this field is underway.

Cell phenotype and behavior strongly depend upon diverse biochemical signals, oxygen supply, mechanical load, topography of the immediate neighborhood, and many other parameters. The optimum values of those parameters are attainable in full only inside a healthy body. Full hepatogenic differentiation of iPSCs or other cells and normal functional activity of differentiated cells can be achieved only after orthotopic transplantation of bioengineered liver and the establishment of its regular connections with the recipient's organism through blood supply, lymph, innervation, and so forth. At present it is not yet clear what quality checks should be performed on engineered liver before transplantation.

\section{Ongoing Clinical Trials of Cell-Based Therapies of Liver Diseases}

Clinical trials of several cell therapy protocols registered at "https://www.clinicaltrials.gov/" site and aimed at treating liver diseases are underway, though they make just a small fraction of all ongoing clinical trials of cell therapy methods. Back in 2014 Moore and coauthors [159] were the first to review results of 33 studies selected by the following relatively strict criteria: median patients number 10 and follow-up for no less than 6 months. This was the first review covering this topic. On August 16, 2016, "Liver failure AND Cell therapy" inquiry revealed 9 registered trials (stage I/II), while "Cell therapy" inquiry revealed 794 trials (stages I/II or III). Interestingly, "Liver failure AND hepatocyte transplantation" query showed just 3 trials of which 1 was withdrawn and the 2 were suspended suggesting problems with deriving sufficient quantities of cells for transplantation or unsatisfactory efficacy. Moore's review and our search results demonstrate that regular clinical testing of cell therapies in hepatology is in its initial phase. Its progress strongly depends upon the results of the current trials.

It is already clear, though, that the methods of cell therapy can be further improved [160,161]. Optimization strategies may include search for the most convenient source of cell material, comparing primary versus cultured cells versus cell lines, combining different cell types, experimenting with culture conditions:number of passages, variable oxygen supply, using genetically manipulated cells capable of induced growth factor release or enhanced in vivo differentiation, trying various administration routes, finding optimal cell numbers, best timing, and number of transplantations, enhancing engraftment of transplanted cells into the liver tissue, and their proliferation after engraftment.

\section{Conclusion}

Data examined in this review demonstrate that adult mammalian liver possesses considerable ability for homeostatic and injury-induced regeneration. The cellular mechanisms of liver regeneration are different from those in other organs in that restoration of the mass of liver parenchyma is achieved by compensatory hypertrophy and hyperplasia of the differentiated parenchymal cells, hepatocytes. Actually, hepatocytes (or 
a fraction of them) may be considered bipotent progenitor cells capable of dedifferentiation, rapid proliferation, and redifferentiation into new hepatocytes and cholangiocytes. In the majority of internal organs resident stem/progenitor cells play a major role in homeostatic regeneration of parenchyma and in the repair of damage caused by disease or trauma. In hepatic tissue their participation in homeostatic and injuryinduced regeneration is still a matter of debate. Participation of blood-borne bone marrow stem cells in the replenishment of liver parenchyma has been proven, though the extent of their participation is limited. Experimental studies of liver regeneration provide valuable guidance to the management of patients with liver failure and to the development of new approaches, including methods of regenerative medicine, that is, cell therapy and tissue engineering.

Cell therapy with hepatocytes is directed to the replenishment of lost parenchymal cells. Transplanted hepatocytes induce paracrine effects as well. Transplantation of HSCs or MSCs promotes regeneration in many tissues throughout the body suggesting that paracrine signals produced by transplanted cells activate stem and certain differentiated cells of various tissues and organs in a similar way. At the cellular level those paracrine signals might induce stem cell proliferation, regulate mesenchymal-to-epithelial transition, suppress differentiation into fibrogenic myofibroblasts, and stimulate macrophage transition to anti-inflammatory phenotype. In addition, rare pluripotent cells present in HSC and MSC cultures may after transplantation differentiate into parenchymal cells of various tissues. All these effects of cell transplantation have been demonstrated in animal liver injury models.

Prospects of transplantation of engineered liver tissue, engineered liver lobe, or whole engineered organ seem good. Different approaches of liver tissue engineering are being developed and innovative tactics are being introduced, but it is not yet clear when clinical trials might begin.

In conclusion, it should be stressed once more that mammals, including humans, possess rather efficient mechanisms of liver regeneration that are activated spontaneously and can be further stimulated by cell therapy. In case of severe damage liver transplantation is the best option. Engineering of a transplantable liver or its part is an enormous challenge, but experimental studies show that it is probably doable.

\section{Competing Interests}

The authors have no conflict of interests to disclose.

\section{Acknowledgments}

This work was supported by the Russian Science Foundation (Grant no. 14-15-00648).

\section{References}

[1] S. L. Friedman, "Liver fibrosis—from bench to bedside," Journal of Hepatology, Supplement, vol. 38, no. 1, pp. S38-S53, 2003.

[2] R. Lozano, M. Naghavi, K. Foreman et al., "Global and regional mortality from 235 causes of death for 20 age groups in 1990 and 2010: a systematic analysis for the Global Burden of Disease Study 2010," The Lancet, vol. 380, no. 9859, pp. 2095-2128, 2012.

[3] S. Caldwell and S. H. Park, "The epidemiology of hepatocellular cancer: from the perspectives of public health problem to tumor biology," Journal of Gastroenterology, vol. 44, no. 19, pp. 96-101, 2009.

[4] WHO, "Hepatitis," 2015, http://www.who.int/campaigns/hepatitis-day/2015/en/.

[5] D. L. Stocum, Regenerative Biology and Medicine, Academic Press, 2006.

[6] D. H. Cormack and A. W. Ham, Ham's Histology, Lippincott Williams \& Wilkins, Philadelphia, Pa, USA, 9th edition, 1987.

[7] S. S. Thorgeirsson, "Hepatic stem cells in liver regeneration," The FASEB Journal, vol. 10, no. 11, pp. 1249-1256, 1996.

[8] N. Fausto, "Liver regeneration and repair: hepatocytes, progenitor cells and stem cells," Hepatology, vol. 39, no. 6, pp. 1477-1487, 2004.

[9] S. Verhulst, J. Best, L. A. van Grunsven, and L. Dollé, "Advances in hepatic stem/progenitor cell biology," EXCLI Journal, vol. 14, pp. 33-47, 2015.

[10] C. Kordes, I. Sawitza, A. Müller-Marbach et al., "CD133+ hepatic stellate cells are progenitor cells," Biochemical and Biophysical Research Communications, vol. 352, no. 2, pp. 410417, 2007.

[11] L. Yang, Y. Jung, A. Omenetti et al., "Fate-mapping evidence that hepatic stellate cells are epithelial progenitors in adult mouse livers," STEM CELLS, vol. 26, no. 8, pp. 2104-2113, 2008.

[12] D. J. Prockop, "Marrow stromal cells as stem cells for nonhematopoietic tissues," Science, vol. 276, no. 5309, pp. 71-74, 1997.

[13] B. E. Petersen, W. C. Bowen, K. D. Patrene et al., "Bone marrow as a potential source of hepatic oval cells," Science, vol. 284, no. 5417, pp. 1168-1170, 1999.

[14] M. R. Alison, R. Poulsom, R. Jeffery et al., "Hepatocytes from non-hepatic adult stem cells," Nature, vol. 406, no. 6793, p. 257, 2000.

[15] C. Yin, K. J. Evason, K. Asahina, and D. Y. R. Stainier, "Hepatic stellate cells in liver development, regeneration, and cancer," The Journal of Clinical Investigation, vol. 123, no. 5, pp. 1902-1910, 2013.

[16] T. Cantz, M. P. Manns, and M. Ott, "Stem cells in liver regeneration and therapy," Cell and Tissue Research, vol. 331, no. 1, pp. 271-282, 2008.

[17] M. Grompe, "Liver stem cells, where art thou?" Cell Stem Cell, vol. 15, no. 3, pp. 257-258, 2014.

[18] W.-Y. Lu, T. G. Bird, L. Boulter et al., "Hepatic progenitor cells of biliary origin with liver repopulation capacity," Nature Cell Biology, vol. 17, no. 8, pp. 971-983, 2015.

[19] R. Gebhardt and A. Hovhannisyan, "Organ patterning in the adult stage: the role of $\mathrm{Wnt} / \beta$-catenin signaling in liver zonation and beyond," Developmental Dynamics, vol. 239, no. 1, pp. 45$55,2010$.

[20] G. M. Higgins and R. M. Anderson, "Experimental pathology of the liver. I. Restoration of the liver of the white rat following partial surgical removal," Archives of Pathology, vol. 12, pp. 186$202,1931$.

[21] J. Kountouras, P. Boura, and N. J. Lygidakis, "Liver regeneration after hepatectomy," Hepato-Gastroenterology, vol. 48, no. 38, pp. 556-562, 2001. 
[22] Y. J. Kwon, K. G. Lee, and D. Choi, "Clinical implications of advances in liver regeneration," Clinical and Molecular Hepatology, vol. 21, no. 1, pp. 7-13, 2015.

[23] N. Fausto, J. S. Campbell, and K. J. Riehle, "Liver regeneration," Hepatology, vol. 43, no. 2, pp. S45-S53, 2006.

[24] G. K. Michalopoulos and Z. Khan, "Liver regeneration, growth factors, and amphiregulin," Gastroenterology, vol. 128, no. 2, pp. 503-506, 2005.

[25] M.-F. Chen, T.-L. Hwang, and C.-F. Hung, "Human liver regeneration after major hepatectomy: a study of liver volume by computed tomography," Annals of Surgery, vol. 213, no. 3, pp. 227-229, 1991.

[26] M. Shimada, T. Matsumata, T. Maeda, H. Itasaka, T. Suehiro, and K. Sugimachi, "Hepatic regeneration following right lobectomy: estimation of regenerative capacity," Surgery Today, vol. 24, no. 1, pp. 44-48, 1994.

[27] T. Ezaki, N. Koyanagi, T. Toyomasu, Y. Ikeda, and K. Sugimachi, "Natural history of hepatectomy regarding liver function: a study of both normal livers and livers with chronic hepatitis and cirrhosis," Hepato-Gastroenterology, vol. 45, no. 23, pp. 17951801, 1998.

[28] P. Kocabayoglu, D. Y. Zhang, K. Kojima, Y. Hoshida, and S. L. Friedman, "Induction and contribution of beta plateletderived growth factor signalling by hepatic stellate cells to liver regeneration after partial hepatectomy in mice," Liver International, vol. 36, no. 6, pp. 874-882, 2016.

[29] Y. A. Minamishima, K. Nakayama, and K.-I. Nakayama, "Recovery of liver mass without proliferation of hepatocytes after partial hepatectomy in Skp2-deficient mice," Cancer Research, vol. 62, no. 4, pp. 995-999, 2002.

[30] S. Haga, M. Ozaki, H. Inoue et al., "The survival pathways phosphatidylinositol-3 kinase (PI3-K)/phosphoinositidedependent protein kinase 1 (PDK1)/Akt modulate liver regeneration through hepatocyte size rather than proliferation," Hepatology, vol. 49, no. 1, pp. 204-214, 2009.

[31] Y. Miyaoka, K. Ebato, H. Kato, S. Arakawa, S. Shimizu, and A. Miyajima, "Hypertrophy and unconventional cell division of hepatocytes underlie liver regeneration," Current biology: $C B$, vol. 22, no. 13, pp. 1166-1175, 2012.

[32] K. Furuyama, Y. Kawaguchi, H. Akiyama et al., "Continuous cell supply from a Sox9-expressing progenitor zone in adult liver, exocrine pancreas and intestine," Nature Genetics, vol. 43, no. 1, pp. 34-41, 2011.

[33] Y. Malato, S. Naqvi, N. Schürmann et al., "Fate tracing of mature hepatocytes in mouse liver homeostasis and regeneration," Journal of Clinical Investigation, vol. 121, no. 12, pp. 4850-4860, 2011.

[34] Y. Zhang, X.-F. Bai, and C.-X. Huang, "Hepatic stem cells: existence and origin," World Journal of Gastroenterology, vol. 9, no. 2, pp. 201-204, 2003.

[35] S. Marubashi, M. Sakon, H. Nagano et al., "Effect of portal hemodynamics on liver regeneration studied in a novel portohepatic shunt rat model," Surgery, vol. 136, no. 5, pp. 1028-1037, 2004.

[36] A. Zimmermann, "Liver regeneration: the emergence of new pathways," Medical Science Monitor: International Medical Journal of Experimental and Clinical Research, vol. 8, no. 3, pp. RA53-RA63, 2002.

[37] T. Sakamoto, Z. Liu, N. Murase et al., "Mitosis and apoptosis in the liver of interleukin-6-deficient mice after partial hepatectomy," Hepatology, vol. 29, no. 2, pp. 403-411, 1999.
[38] J. Rozga, "Hepatocyte proliferation in health and in liver failure," Medical Science Monitor, vol. 8, no. 2, pp. RA32-RA38, 2002.

[39] N. Fausto and J. S. Campbell, "The role of hepatocytes and oval cells in liver regeneration and repopulation," Mechanisms of Development, vol. 120, no. 1, pp. 117-130, 2003.

[40] R. Gebhardt, A. Baldysiak-Figiel, V. Krügel, E. Ueberham, and F. Gaunitz, "Hepatocellular expression of glutamine synthetase: an indicator of morphogen actions as master regulators of zonation in adult liver," Progress in Histochemistry and Cytochemistry, vol. 41, no. 4, pp. 201-266, 2007.

[41] T. Matsuo, S. Yamaguchi, S. Mitsui, A. Emi, F. Shimoda, and H. Okamura, "Control mechanism of the circadian clock for timing of cell division in vivo," Science, vol. 302, no. 5643, pp. 255-259, 2003

[42] Y. Zou, Q. Bao, S. Kumar, M. Hu, G.-Y. Wang, and G. Dai, “Four waves of hepatocyte proliferation linked with three waves of hepatic fat accumulation during partial hepatectomy-induced liver regeneration," PLoS ONE, vol. 7, no. 2, Article ID e30675, 2012.

[43] C. Meijer, M. J. Wiezer, A. M. Diehl et al., "Kupffer cell depletion by $\mathrm{CI}_{2} \mathrm{MDP}$-liposomes alters hepatic cytokine expression and delays liver regeneration after partial hepatectomy," Liver, vol. 20, no. 1, pp. 66-77, 2000.

[44] J. Yang, L. E. Mowry, K. N. Nejak-Bowen et al., " $\beta$-Catenin signaling in murine liver zonation and regeneration: a Wnt-Wnt situation!," Hepatology, vol. 60, no. 3, pp. 964-976, 2014.

[45] S. Amini-Nik, E. Cambridge, W. Yu et al., “ $\beta$-Catenin-regulated myeloid cell adhesion and migration determine wound healing," Journal of Clinical Investigation, vol. 124, no. 6, pp. 25992610, 2014.

[46] G. K. Michalopoulos, "Liver regeneration after partial hepatectomy: critical analysis of mechanistic dilemmas," American Journal of Pathology, vol. 176, no. 1, pp. 2-13, 2010.

[47] B.-S. Ding, D. J. Nolan, J. M. Butler et al., "Inductive angiocrine signals from sinusoidal endothelium are required for liver regeneration," Nature, vol. 468, no. 7321, pp. 310-315, 2010.

[48] T. Itoh and A. Miyajima, "Liver regeneration by stem/progenitor cells," Hepatology, vol. 59, no. 4, pp. 1617-1626, 2014.

[49] R. P. Evarts, P. Nagy, E. Marsden, and S. S. Thorgeirsson, "A precursor-product relationship exists between oval cells and hepatocytes in rat liver," Carcinogenesis, vol. 8, no. 11, pp. 17371740, 1987.

[50] M. D. Dabeva and D. A. Shafritz, "Activation, proliferation, and differentiation of progenitor cells into hepatocytes in the Dgalactosamine model of liver regeneration," American Journal of Pathology, vol. 143, no. 6, pp. 1606-1620, 1993.

[51] N. Fausto, "Liver regeneration," Journal of Hepatology, vol. 32, supplement 1, pp. 19-31, 2000.

[52] L. Libbrecht and T. Roskams, "Hepatic progenitor cells in human liver diseases," Seminars in Cell and Developmental Biology, vol. 13, no. 6, pp. 389-396, 2002.

[53] T. A. Roskams, N. D. Theise, C. Balabaud et al., "Nomenclature of the finer branches of the biliary tree: canals, ductules, and ductular reactions in human livers," Hepatology, vol. 39, no. 6, pp. 1739-1745, 2004.

[54] N. D. Theise, R. Saxena, B. C. Portmann et al., "The canals of Hering and hepatic stem cells in humans," Hepatology, vol. 30, no. 6, pp. 1425-1433, 1999.

[55] M. Fujita, H. Furukawa, M. Hattori, S. Todo, Y. Ishida, and K. Nagashima, "Sequential observation of liver cell regeneration after massive hepatic necrosis in auxiliary partial orthotopic 
liver transplantation," Modern Pathology, vol. 13, no. 2, pp. 152$157,2000$.

[56] L. E. Schmidt and K. Dalhoff, "Alpha-fetoprotein is a predictor of outcome in acetaminophen-induced liver injury," Hepatology, vol. 41, no. 1, pp. 26-31, 2005.

[57] T. A. Roskams, L. Libbrecht, and V. J. Desmet, "Progenitor cells in diseased human liver," Seminars in Liver Disease, vol. 23, no. 4, pp. 385-396, 2003.

[58] O. Falkowski, H. J. An, I. A. Ianus et al., "Regeneration of hepatocyte 'buds' in cirrhosis from intrabiliary stem cells," Journal of Hepatology, vol. 39, no. 3, pp. 357-364, 2003.

[59] G. K. Michalopoulos, "Advances in liver regeneration," Expert Review of Gastroenterology and Hepatology, vol. 8, no. 8, pp. 897-907, 2014.

[60] A. W. Duncan, C. Dorrell, and M. Grompe, "Stem cells and liver regeneration," Gastroenterology, vol. 137, no. 2, pp. 466-481, 2009.

[61] M. Huch, C. Dorrell, S. F. Boj et al., "In vitro expansion of single Lgr $^{+}$liver stem cells induced by Wnt-driven regeneration," Nature, vol. 494, no. 7436, pp. 247-250, 2013.

[62] M. Huch, H. Gehart, R. van Boxtel et al., "Long-term culture of genome-stable bipotent stem cells from adult human liver," Cell, vol. 160, no. 1-2, pp. 299-312, 2015.

[63] A. Jakubowski, C. Ambrose, M. Parr et al., "TWEAK induces liver progenitor cell proliferation," The Journal of Clinical Investigation, vol. 115, no. 9, pp. 2330-2340, 2005.

[64] R. P. Evarts, Z. Hu, K. Fujio, E. R. Marsden, and S. S. Thorgeirsson, "Activation of hepatic stem cell compartment in the rat: role of transforming growth factor alpha, hepatocyte growth factor, and acidic fibroblast growth factor in early proliferation," Cell Growth and Differentiation: The Molecular Biology Journal of the American Association for Cancer Research, vol. 4, no. 7, pp. 555561, 1993.

[65] Z. Hu, R. P. Evarts, K. Fujio et al., "Expression of transforming growth factor alpha/epidermal growth factor receptor, hepatocyte growth factor/c-met and acidic fibroblast growth factor/fibroblast growth factor receptors during hepatocarcinogenesis," Carcinogenesis, vol. 17, no. 5, pp. 931-938, 1996.

[66] K. Isse, A. Lesniak, K. Grama et al., "Preexisting epithelial diversity in normal human livers: a tissue-tethered cytometric analysis in portal/periportal epithelial cells," Hepatology, vol. 57, no. 4, pp. 1632-1643, 2013.

[67] G. K. Michalopoulos, L. Barua, and W. C. Bowen, "Transdifferentiation of rat hepatocytes into biliary cells after bile duct ligation and toxic biliary injury," Hepatology, vol. 41, no. 3, pp. 535-544, 2005.

[68] P. B. Limaye, W. C. Bowen, A. V. Orr, J. Luo, G. C. Tseng, and G. K. Michalopoulos, "Mechanisms of hepatocyte growth factormediated and epidermal growth factor-mediated signaling in transdifferentiation of rat hepatocytes to biliary epithelium," Hepatology, vol. 47, no. 5, pp. 1702-1713, 2008.

[69] K. Yanger, Y. Zong, L. R. Maggs et al., "Robust cellular reprogramming occurs spontaneously during liver regeneration," Genes and Development, vol. 27, no. 7, pp. 719-724, 2013.

[70] F. Clotman, P. Jacquemin, N. Plumb-Rudewiez et al., "Control of liver cell fate decision by a gradient of TGF $\beta$ signaling modulated by Onecut transcription factors," Genes \& Development, vol. 19, no. 16, pp. 1849-1854, 2005.

[71] R. Carpentier, R. E. Suer, N. van Hul et al., "Embryonic ductal plate cells give rise to cholangiocytes, periportal hepatocytes, and adult liver progenitor cells," Gastroenterology, vol. 141, no. 4, pp. 1432-1438.e4, 2011.
[72] V. J. Desmet, "Congenital diseases of intrahepatic bile ducts: variations on the theme 'ductal plate malformation"' Hepatology, vol. 16, no. 4, pp. 1069-1083, 1992.

[73] P. B. Limaye, G. Alarcón, A. L. Walls et al., "Expression of specific hepatocyte and cholangiocyte transcription factors in human liver disease and embryonic development," Laboratory Investigation, vol. 88, no. 8, pp. 865-872, 2008.

[74] T. Roskams, R. De Vos, J. J. Van Den Oord, and V. Desmet, "Cells with neuroendocrine features in regenerating human liver," APMIS, Supplement, vol. 99, no. 23, pp. 32-39, 1991.

[75] V. Desmet, T. Roskams, and P. Van Eyken, "Ductular reaction in the liver," Pathology-Research and Practice, vol. 191, no. 6, pp. 513-524, 1995.

[76] A. Hattoum, E. Rubin, A. Orr, and G. K. Michalopoulos, "Expression of hepatocyte epidermal growth factor receptor, FAS and glypican 3 in EpCAM-positive regenerative clusters of hepatocytes, cholangiocytes, and progenitor cells in human liver failure," Human Pathology, vol. 44, no. 5, pp. 743-749, 2013.

[77] J. R. Schaub, Y. Malato, C. Gormond, and H. Willenbring, "Evidence against a stem cell origin of new hepatocytes in a common mouse model of chronic liver injury," Cell Reports, vol. 8, no. 4, pp. 933-939, 2014.

[78] K. Yanger, D. Knigin, Y. Zong et al., "Adult hepatocytes are generated by self-duplication rather than stem cell differentiation," Cell Stem Cell, vol. 15, no. 3, pp. 340-349, 2014.

[79] D. Rodrigo-Torres, S. Affò, M. Coll et al., “The biliary epithelium gives rise to liver progenitor cells," Hepatology, vol. 60, no. 4, pp. 1367-1377, 2014.

[80] B. D. Tarlow, M. J. Finegold, and M. Grompe, "Clonal tracing of Sox9+ liver progenitors in mouse oval cell injury," Hepatology, vol. 60, no. 1, pp. 278-289, 2014.

[81] J. Font-Burgada, S. Shalapour, S. Ramaswamy et al., "Hybrid periportal hepatocytes regenerate the injured liver without giving rise to cancer," Cell, vol. 162, no. 4, pp. 766-779, 2015.

[82] N. Tanimizu, N. Ichinohe, M. Ishii et al., "Liver progenitors isolated from adult healthy mouse liver efficiently differentiate to functional hepatocytes in vitro and repopulate liver tissue," Stem Cells, vol. 34, no. 12, pp. 2889-2901, 2016.

[83] G. S. Pahal, E. Jauniaux, C. Kinnon, A. J. Thrasher, and C. H. Rodeck, "Normal development of human fetal hematopoiesis between eight and seventeen weeks' gestation," American Journal of Obstetrics and Gynecology, vol. 183, no. 4, pp. 1029-1034, 2000.

[84] P. M. Lansdorp, W. Dragowska, and H. Mayani, “Ontogenyrelated changes in proliferative potential of human hematopoietic cells," The Journal of Experimental Medicine, vol. 178, no. 3, pp. 787-791, 1993.

[85] H. Taniguchi, T. Toyoshima, K. Fukao, and H. Nakauchi, "Presence of hematopoietic stem cells in the adult liver," Nature Medicine, vol. 2, no. 2, pp. 198-203, 1996.

[86] E. Lagasse, H. Connors, M. Al-Dhalimy et al., "Purified hematopoietic stem cells can differentiate into hepatocytes in vivo," Nature Medicine, vol. 6, no. 11, pp. 1229-1234, 2000.

[87] M. Ruhnke, A. K. Nussler, H. Ungefroren et al., "Human monocyte-derived neohepatocytes: a promising alternative to primary human hepatocytes for autologous cell therapy," Transplantation, vol. 79, no. 9, pp. 1097-1103, 2005.

[88] H. Gilgenkrantz, "Mesenchymal stem cells: an alternative source of hepatocytes?" Hepatology, vol. 40, no. 6, pp. 1256$1259,2004$. 
[89] K.-D. Lee, T. K.-C. Kuo, J. Whang-Peng et al., "In vitro hepatic differentiation of human mesenchymal stem cells," Hepatology, vol. 40, no. 6, pp. 1275-1284, 2004.

[90] B. E. Petersen, J. P. Goff, J. S. Greenberger, and G. K. Michalopoulos, "Hepatic oval cells express the hematopoietic stem cell marker Thy-1 in the rat," Hepatology, vol. 27, no. 2, pp. 433-445, 1998.

[91] N. D. Theise, S. Badve, R. Saxena et al., "Derivation of hepatocytes from bone marrow cells in mice after radiation-induced myeloablation," Hepatology, vol. 31, no. 1, pp. 235-240, 2000.

[92] C. Guha, A. Sharma, S. Gupta et al., "Amelioration of radiationinduced liver damage in partially hepatectomized rats by hepatocyte transplantation," Cancer Research, vol. 59, no. 23, pp. 5871-5874, 1999.

[93] H. Fujii, T. Hirose, S. Oe et al., "Contribution of bone marrow cells to liver regeneration after partial hepatectomy in mice," Journal of Hepatology, vol. 36, no. 5, pp. 653-659, 2002.

[94] Y. Yamada, E. Nishimoto, H. Mitsuya, and Y. Yonemura, "In vitro transdifferentiation of adult bone marrow Sca- ${ }^{+} \mathrm{cKit}^{-}$ cells cocultured with fetal liver cells into hepatic-like cells without fusion," Experimental Hematology, vol. 34, no. 1, pp. 97106, 2006.

[95] S. Khurana and A. Mukhopadhyay, "In vitro transdifferentiation of adult hematopoietic stem cells: an alternative source of engraftable hepatocytes," Journal of Hepatology, vol. 49, no. 6, pp. 998-1007, 2008.

[96] K. Oh, S. Y. Shon, M. W. Seo et al., "Murine Scal ${ }^{+} \mathrm{Lin}^{-}$bone marrow contains an endodermal precursor population that differentiates into hepatocytes," Experimental and Molecular Medicine, vol. 47, article e187, 2015.

[97] P. Goichberg, "Current understanding of the pathways involved in adult stem and progenitor cell migration for tissue homeostasis and repair," Stem Cell Reviews and Reports, vol. 12, no. 4, pp. 421-437, 2016.

[98] X. Wang, H. Willenbring, Y. Akkari et al., "Cell fusion is the principal source of bone-marrow-derived hepatocytes," Nature, vol. 422, no. 6934, pp. 897-901, 2003.

[99] G. Vassilopoulos, P.-R. Wang, and D. W. Russell, “Transplanted bone marrow regenerates liver by cell fusion," Nature, vol. 422, no. 6934, pp. 901-904, 2003.

[100] L. Li, Z. Zeng, Z. Qi et al., "Natural killer cells-produced ifn$\gamma$ improves bone marrow-derived hepatocytes regeneration in murine liver failure model," Scientific Reports, vol. 5, Article ID 13687, 2015.

[101] Y. Kuroda, M. Kitada, S. Wakao et al., "Unique multipotent cells in adult human mesenchymal cell populations," Proceedings of the National Academy of Sciences of the United States of America, vol. 107, no. 19, pp. 8639-8643, 2010.

[102] H. Katagiri, Y. Kushida, M. Nojima et al., "A distinct subpopulation of bone marrow mesenchymal stem cells, muse cells, directly commit to the replacement of liver components," American Journal of Transplantation, vol. 16, no. 2, pp. 468-483, 2016.

[103] R. E. Schwartz, M. Reyes, L. Koodie et al., "Multipotent adult progenitor cells from bone marrow differentiate into functional hepatocyte-like cells," Journal of Clinical Investigation, vol. 109, no. 10, pp. 1291-1302, 2002.

[104] M. Kucia, R. Reca, F. R. Campbell et al., "A population of very small embryonic-like (VSEL) CXCR $4^{+}$SSEA- $1^{+}$Oct $-4^{+}$stem cells identified in adult bone marrow," Leukemia, vol. 20, no. 5, pp. 857-869, 2006.
[105] A. Terzic, M. A. Pfenning, G. J. Gores, and C. M. Harper, "Regenerative medicine build-out," Stem Cells Translational Medicine, vol. 4, no. 12, pp. 1373-1379, 2015.

[106] A. S. Mao and D. J. Mooney, "Regenerative medicine: current therapies and future directions," Proceedings of the National Academy of Sciences of the United States of America, vol. 112, no. 47, pp. 14452-14459, 2015.

[107] K. N. Yarygin, A. Y. Lupatov, and I. V. kholodenko, "Cell-based therapies of liver diseases: Age-related challenges," Clinical Interventions in Aging, vol. 10, pp. 1909-1924, 2015.

[108] G. J. Christ, J. M. Saul, M. E. Furth, and K.-E. Andersson, “The pharmacology of regenerative medicine," Pharmacological Reviews, vol. 65, no. 3, pp. 1091-1133, 2013.

[109] H. Choi and D. S. Lee, "Illuminating the physiology of extracellular vesicles," Stem Cell Research and Therapy, vol. 7, no. 1, article 55, 2016.

[110] S. Gupta, E. Aragona, R. P. Vemuru, K. K. Bhargava, R. D. Burk, and J. R. Chowdhury, "Permanent engraftment and function of hepatocytes delivered to the liver: implications for gene therapy and liver repopulation," Hepatology, vol. 14, no. 1, pp. 144-149, 1991.

[111] A. Weber, M.-T. Groyer-Picard, D. Franco, and I. Dagher, "Hepatocyte transplantation in animal models," Liver Transplantation, vol. 15, no. 1, pp. 7-14, 2009.

[112] R. D. Hughes, R. R. Mitry, and A. Dhawan, "Current status of hepatocyte transplantation," Transplantation, vol. 93, no. 4, pp. 342-347, 2012.

[113] R. C. Huebert and J. Rakela, "Cellular therapy for liver disease," Mayo Clinic Proceedings, vol. 89, no. 3, pp. 414-424, 2014.

[114] A. Dhawan, J. Puppi, R. D. Hughes, and R. R. Mitry, "Human hepatocyte transplantation: current experience and future challenges," Nature Reviews Gastroenterology and Hepatology, vol. 7, no. 5, pp. 288-298, 2010.

[115] G. A. A. Nibourg, R. Hoekstra, T. V. van der Hoeven et al., "Increased hepatic functionality of the human hepatoma cell line HepaRG cultured in the AMC bioreactor," International Journal of Biochemistry and Cell Biology, vol. 45, no. 8, pp. 18601868, 2013.

[116] S. Gupta, "Hog heaven on the road to liver cell therapy," Gastroenterology, vol. 132, no. 1, pp. 450-453, 2007.

[117] H. Nagata, R. Nishitai, C. Shirota et al., "Prolonged survival of porcine hepatocytes in cynomolgus monkeys," Gastroenterology, vol. 132, no. 1, pp. 321-329, 2007.

[118] Y. Enami, B. Joseph, S. Bandi, J. Lin, and S. Gupta, "Molecular perturbations restrict potential for liver repopulation of hepatocytes isolated from non-heart-beating donor rats," Hepatology, vol. 55, no. 4, pp. 1182-1192, 2012.

[119] F. G. Sagias, R. R. Mitry, R. D. Hughes et al., "N-acetylcysteine improves the viability of human hepatocytes isolated from severely steatotic donor liver tissue," Cell Transplantation, vol. 19, no. 11, pp. 1487-1492, 2010.

[120] G. Levy, D. Bomze, S. Heinz et al., "Long-term culture and expansion of primary human hepatocytes," Nature Biotechnology, vol. 33, no. 12, pp. 1264-1271, 2015.

[121] M. Huch, H. Gehart, R. Van Boxtel et al., "Long-term culture of genome-stable bipotent stem cells from adult human liver," Cell, vol. 160, no. 1-2, pp. 299-312, 2015.

[122] K. Takahashi, K. Tanabe, M. Ohnuki et al., "Induction of pluripotent stem cells from adult human fibroblasts by defined factors," Cell, vol. 131, no. 5, pp. 861-872, 2007. 
[123] Z. Song, J. Cai, Y. Liu et al., "Efficient generation of hepatocytelike cells from human induced pluripotent stem cells," Cell Research, vol. 19, no. 11, pp. 1233-1242, 2009.

[124] K. Si-Tayeb, F. K. Noto, M. Nagaoka et al., "Highly efficient generation of human hepatocyte-like cells from induced pluripotent stem cells," Hepatology, vol. 51, no. 1, pp. 297-305, 2010.

[125] G. J. Sullivan, D. C. Hay, I.-H. Park et al., "Generation of functional human hepatic endoderm from human induced pluripotent stem cells," Hepatology, vol. 51, no. 1, pp. 329-335, 2010.

[126] N. R. F. Hannan, C.-P. Segeritz, T. Touboul, and L. Vallier, "Production of hepatocyte-like cells from human pluripotent stem cells," Nature Protocols, vol. 8, no. 2, pp. 430-437, 2013.

[127] K. Sasaki, "Large-scale generation of differentiated cells to achieve regenerative medicine," Stem Cell Research and Therapy, vol. 5, no. 1, article 10, 2014.

[128] E. W. Kuijk, S. Rasmussen, F. Blokzijl et al., "Generation and characterization of rat liver stem cell lines and their engraftment in a rat model of liver failure," Scientific Reports, vol. 6, Article ID 22154, 2016.

[129] N. Fausto, J. S. Campbell, and K. J. Riehle, "Liver regeneration," Journal of Hepatology, vol. 57, no. 3, pp. 692-694, 2012.

[130] J. A. Thomas, C. Pope, D. Wojtacha et al., "Macrophage therapy for murine liver fibrosis recruits host effector cells improving fibrosis, regeneration, and function," Hepatology, vol. 53, no. 6, pp. 2003-2015, 2011.

[131] A.-R. N. Zekri, H. Salama, E. Medhat et al., "The impact of repeated autologous infusion of haematopoietic stem cells in patients with liver insufficiency," Stem Cell Research and Therapy, vol. 6, no. 1, article 118, 2015.

[132] S. J. Forbes and P. N. Newsome, "New horizons for stem cell therapy in liver disease," Journal of Hepatology, vol. 56, no. 2, pp. 496-499, 2012.

[133] B. Parekkadan and J. M. Milwid, "Mesenchymal stem cells as therapeutics," Annual Review of Biomedical Engineering, vol. 12, pp. 87-117, 2010.

[134] M. Gnecchi, P. Danieli, G. Malpasso, and M. C. Ciuffreda, "Paracrine mechanisms of mesenchymal stem cells in tissue repair," Methods in Molecular Biology, vol. 1416, pp. 123-146, 2016.

[135] D. G. Phinney and D. J. Prockop, "Concise review: mesenchymal stem/multipotent stromal cells: the state of transdifferentiation and modes of tissue repair-current views," STEM CELLS, vol. 25, no. 11, pp. 2896-2902, 2007.

[136] E. Jameson, "Cellular transplantation for liver diseases," Gastroenterology Research, vol. 1, no. 1, pp. 8-13, 2008.

[137] A. King, D. Barton, H. A. Beard et al., "REpeated autologous infusions of stem cells in cirrhosis (REALISTIC): a multicentre, phase II, open-label, randomised controlled trial of repeated autologous infusions of granulocyte colony-stimulating factor (GCSF) mobilised CD133+ bone marrow stem cells in patients with cirrhosis. A study protocol for a randomised controlled trial," BMJ Open, vol. 5, no. 3, Article ID e007700, 2015.

[138] X.-R. Ma, Y.-L. Tang, M. Xuan, Z. Chang, X.-Y. Wang, and X.-H. Liang, "Transplantation of autologous mesenchymal stem cells for end-stage liver cirrhosis: a meta-analysis based on seven controlled trials," Gastroenterology Research and Practice, vol. 2015, Article ID 908275, 10 pages, 2015.

[139] E. Fiore, M. Malvicini, J. Bayo et al., "Involvement of hepatic macrophages in the antifibrotic effect of IGF-I-overexpressing mesenchymal stromal cells," Stem Cell Research \& Therapy, vol. 7, article 172, 2016.

[140] S. Winkler, M. Hempel, S. Brückner, H.-M. Tautenhahn, R. Kaufmann, and B. Christ, "Identification of pathways in liver repair potentially targeted by secretory proteins from human mesenchymal stem cells," International Journal of Molecular Sciences, vol. 17, no. 7, article E1099, 2016.

[141] F. Mußbach, U. Settmacher, O. Dirsch, C. Xie, and U. Dahmen, "Bioengineered livers: a new tool for drug testing and a promising solution to meet the growing demand for donor organs," European Surgical Research, vol. 57, no. 3-4, pp. 224239, 2016.

[142] S. Y. Lee, H. J. Kim, and D. Choi, "Cell sources, liver support systems and liver tissue engineering: alternatives to liver transplantation," International Journal of Stem Cells, vol. 8, no. 1, pp. 36-47, 2015.

[143] P. M. Crapo, T. W. Gilbert, and S. F. Badylak, "An overview of tissue and whole organ decellularization processes," Biomaterials, vol. 32, no. 12, pp. 3233-3243, 2011.

[144] B. E. Uygun, A. Soto-Gutierrez, H. Yagi et al., "Organ reengineering through development of a transplantable recellularized liver graft using decellularized liver matrix," Nature Medicine, vol. 16, no. 7, pp. 814-820, 2010.

[145] A. Soto-Gutierrez, L. Zhang, C. Medberry et al., "A whole-organ regenerative medicine approach for liver replacement," Tissue Engineering Part C: Methods, vol. 17, no. 6, pp. 677-686, 2011.

[146] P. M. Baptista, M. M. Siddiqui, G. Lozier, S. R. Rodriguez, A. Atala, and S. Soker, "The use of whole organ decellularization for the generation of a vascularized liver organoid," Hepatology, vol. 53, no. 2, pp. 604-617, 2011.

[147] O. Barakat, S. Abbasi, G. Rodriguez et al., "Use of decellularized porcine liver for engineering humanized liver organ," Journal of Surgical Research, vol. 173, no. 1, pp. e11-e25, 2012.

[148] Y. Chen, C. Yu, G. Lv et al., "Rapid large-scale culturing of microencapsulated hepatocytes: a promising approach for cellbased hepatic support," Transplantation Proceedings, vol. 46, no. 5, pp. 1649-1657, 2014.

[149] R. Chang, K. Emami, H. Wu, and W. Sun, "Biofabrication of a three-dimensional liver micro-organ as an in vitro drug metabolism model," Biofabrication, vol. 2, no. 4, Article ID 045004, 2010.

[150] T. Ikegami and Y. Maehara, "Transplantation: 3D printing of the liver in living donor liver transplantation," Nature Reviews. Gastroenterology and Hepatology, vol. 10, no. 12, pp. 697-698, 2013.

[151] M. C. Hansel, J. C. Davila, M. Vosough et al., "The use of induced pluripotent stem cells for the study and treatment of liver diseases," Current Protocols in Toxicology, vol. 67, pp. 14.13.1-14.13.27, 2016.

[152] S.-J. Kang, H.-M. Lee, Y.-I. Park et al., "Chemically induced hepatotoxicity in human stem cell-induced hepatocytes compared with primary hepatocytes and HepG2," Cell Biology and Toxicology, vol. 32, no. 5, pp. 403-417, 2016.

[153] B. Wang, A. E. Jakus, P. M. Baptista et al., "Functional maturation of induced pluripotent stem cell hepatocytes in extracellular matrix - a comparative analysis of bioartificial liver microenvironments," Stem Cells Translational Medicine, vol. 5, no. 9, pp. 1257-1267, 2016.

[154] M. Caralt, E. Velasco, A. Lanas, and P. M. Baptista, "Liver bioengineering: from the stage of liver decellularized matrix to the multiple cellular actors and bioreactor special effects," Organogenesis, vol. 10, no. 2, pp. 250-259, 2014. 
[155] N. Nakatsuji, F. Nakajima, and K. Tokunaga, "HLA-haplotype banking and iPS cells," Nature Biotechnology, vol. 26, no. 7, pp. 739-740, 2008.

[156] C. J. Taylor, S. Peacock, A. N. Chaudhry, J. A. Bradley, and E. M. Bolton, "Generating an iPSC bank for HLA-matched tissue transplantation based on known donor and recipient hla types," Cell Stem Cell, vol. 11, no. 2, pp. 147-152, 2012.

[157] M. Turner, S. Leslie, N. G. Martin et al., "Toward the development of a global induced pluripotent stem cell library," Cell Stem Cell, vol. 13, no. 4, pp. 382-384, 2013.

[158] S. Solomon, F. Pitossi, and M. S. Rao, "Banking on iPSC- is it doable and is it worthwhile," Stem Cell Reviews and Reports, vol. 11, no. 1, pp. 1-10, 2015.

[159] J. K. Moore, B. M. Stutchfield, and S. J. Forbes, "Systematic review: the effects of autologous stem cell therapy for patients with liver disease," Alimentary Pharmacology and Therapeutics, vol. 39, no. 7, pp. 673-685, 2014.

[160] S. J. Forbes, S. Gupta, and A. Dhawan, "Cell therapy for liver disease: from liver transplantation to cell factory," Journal of Hepatology, vol. 62, supplement 1, pp. S157-S169, 2015.

[161] S. Liu, J. Zhou, X. Zhang et al., "Strategies to optimize adult stem cell therapy for tissue regeneration," International Journal of Molecular Sciences, vol. 17, no. 6, article E982, 2016. 


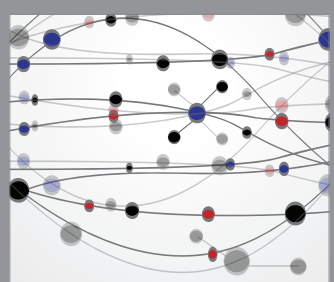

The Scientific World Journal
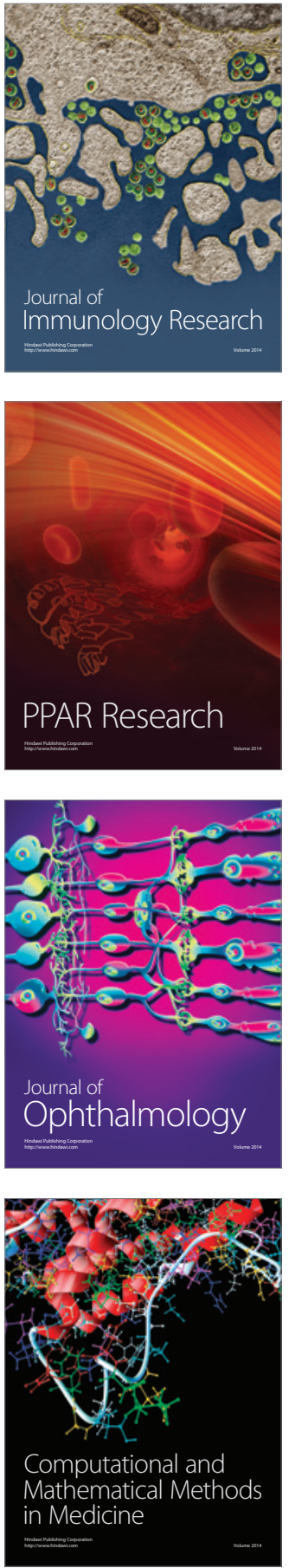

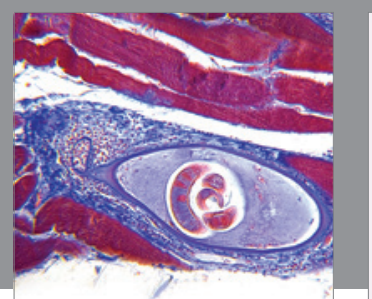

Gastroenterology Research and Practice
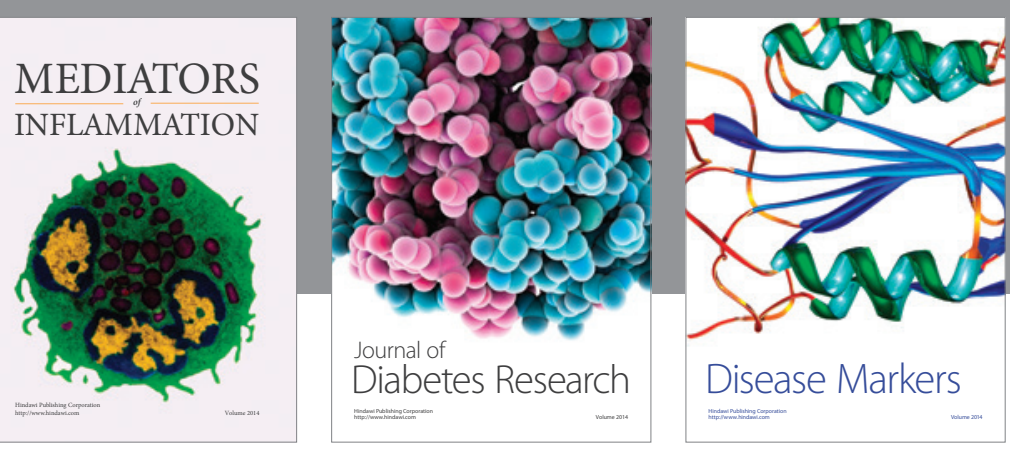

Disease Markers

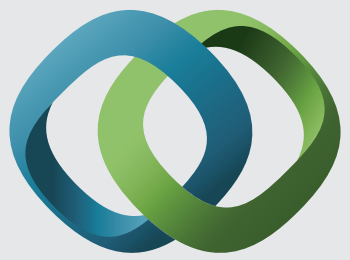

\section{Hindawi}

Submit your manuscripts at

https://www.hindawi.com
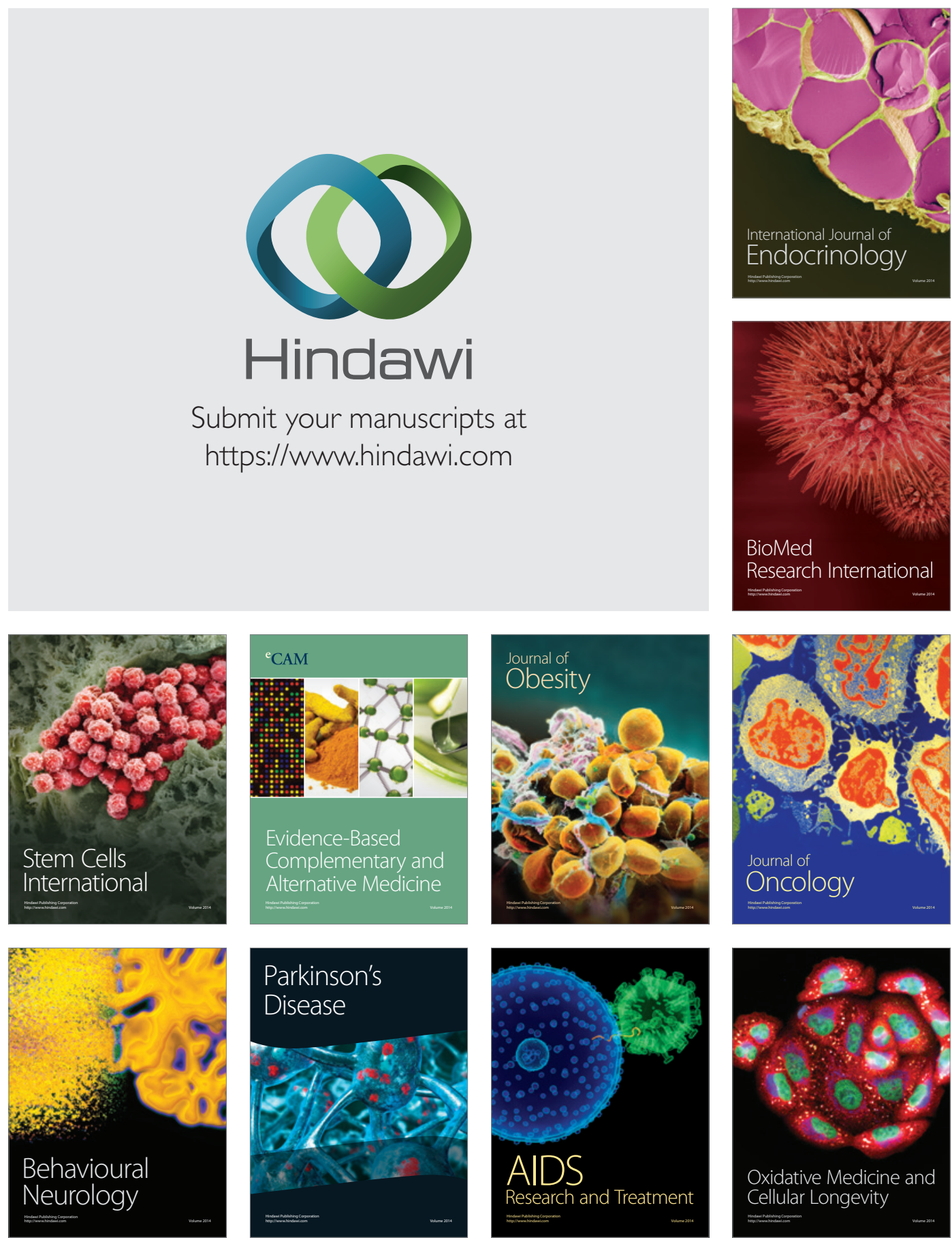